\title{
Genetic drivers of cerebral blood flow dysfunction in traumatic brain injury: a speculative synthesis
}

Frederick A. Zeiler, ${ }^{1-3 *}$ Eric P. Thelin, ${ }^{4,5}$ Joseph Donnelly, ${ }^{4}$ Andrew R. Stevens, ${ }^{1}$ Peter Smielewski, ${ }^{4}$ Marek Czosnyka, ${ }^{4,7}$ Peter J. Hutchinson ${ }^{4}$ and David K. Menon ${ }^{1}$

1. Division of Anaesthesia, Addenbrooke's Hospital, University of Cambridge, Cambridge, UK

2. Department of Surgery, Rady Faculty of Health Sciences, University of Manitoba, Winnipeg, MB, Canada

3. Clinician Investigator Program, Rady Faculty of Health Sciences, University of Manitoba, Winnipeg, MB, Canada

4. Division of Neurosurgery, Department of Clinical Neurosciences, Addenbrooke's Hospital, University of Cambridge, Cambridge, UK

5. Department of Clinical Neuroscience, Karolinska Institute, Stockholm, Sweden

6. Institute of Electronic Systems, Warsaw University of Technology, Warsaw, Poland

e-mail: umzeiler@myumanitoba.ca 


\section{Abstract}

Cerebral autoregulatory dysfunction after traumatic brain injury (TBI) is strongly linked to poor global outcome in patients at 6 months after injury. However, our understanding of what drives this dysfunction is limited. Genetic variation among individuals within a population gives rise to single nucleotide polymorphisms (SNPs) that have the potential to influence a given patient's cerebrovascular response to an injury. Associations have been reported between a variety of genetic polymorphisms and global outcome in patients with TBI, but few studies have explored the association between genetics and cerebrovascular function after injury. In this Review, we explore polymorphisms that might play an important part in cerebral autoregulatory capacity after TBI. We outline a variety of SNPs, their biological substrates and their potential role in mediating cerebrovascular reactivity. A number of candidate polymorphisms exist in genes that are involved in myogenic, endothelial, metabolic and neurogenic vascular responses to injury. Furthermore, polymorphisms in genes involved in inflammation, the central autonomic response and spreading cortical depression might drive cerebrovascular reactivity. Identification of candidate genes involved in cerebral autoregulation after TBI provides a platform and rationale for further prospective investigation of the link between genetic polymorphisms and autoregulatory function. 


\section{$\underline{\text { Key Points }}$}

1. Impaired cerebral autoregulation after traumatic brain injury (TBI) has been linked to poor global outcome; mechanisms involved in the regulation of cerebrovascular reactivity are complex and multifaceted, both in the healthy and diseased state.

2. Single nucleotide polymorphisms (SNPs) related to myogenic, endothelial, neurotransmitter and metabolic mechanisms of cerebrovascular biology are all likely to contribute to cerebrovascular reactivity in the setting of TBI.

3. To date, polymorphisms related to nitric oxide synthase and the renin-angiotensin system have been studied most extensively in relation to cerebral autoregulatory dysfunction both in healthy individuals and in those with TBI, with specific mutations linked to impaired function.

4. Other polymorphisms related to inflammatory response to injury, central autonomic response and spreading cortical depression carry the potential to affect cerebral autoregulation.

5. Numerous candidate polymorphisms exist that might be involved in cerebral autoregulation and vascular reactivity.

6. Future prospective multi-centre Bayesian analysis of genotype data from TBI populations will be required to better understand potential mechanisms involved in impaired vascular reactivity and develop therapeutic targets. 


\section{[H1] Introduction}

Traumatic brain injury (TBI) is global public health concern, with an estimated 50 million people undergoing this injury per year. ${ }^{1,2}$ TBI has a bimodal age distribution, predominantly occurring in the young and elderly, ${ }^{3}$ and poses a major disability and economic burden worldwide. ${ }^{1}$ The main causes of TBI include, but are not limited to, motor vehicle incidents, falls and assaults. ${ }^{1,3}$ TBI occurs as a spectrum of disease, ranging from milder forms such as concussion, which carries potential long-term morbidity, to severe injury that requires admission to the intensive care unit (ICU), with a mortality of 30 to $40 \% .{ }^{1,4,5}$ The majority of the mortality exists within the populations of moderate to severe $\mathrm{TBI}$, and is attributed to the primary injury, secondary insults (such as hypoxia or hypotension) and the development of complications, including those localized to the cranial vault and systemic issues associated with critical illness. ${ }^{5}$

Impaired cerebral autoregulation after moderate and severe TBI is one such physiological complication associated with patient outcome. The link between impaired cerebral autoregulation in moderate and severe TBI and poor patient outcome in TBI is now well established, ${ }^{6-8}$ with area under the receiver operating curve in the range of 0.6 to 0.8 in association with mortality and morbidity at 6 months post injury. ${ }^{6,7}$ Invasive and non-invasive multi-modal techniques, such as transcranial Doppler (TCD) ultrasonography or intra-cranial pressure monitoring, enable us to continuously follow metrics of cerebral autoregulatory capacity in patients with moderate or severe $\mathrm{TBI}^{9,10}$ and provide real-time assessment of vascular reactivity through the acute and sub-acute phase of illness. However, an improved understanding of the biological mechanisms underlying autoregulatory failure in TBI is needed to enable the development of interventions that mitigate this pathogenic process.

Exploration of genetic associations in TBI provides a means to relate molecular pathogenic mechanisms to human disease. Many of the insights in this area have come from animal studies ${ }^{11-13}$ and studies on the effects of genetics on outcomes in adult TBI. ${ }^{14}$ However, data in humans are currently limited in this area, despite the availability of several approaches to explore human disease biology in $\mathrm{TBI}^{15}{ }^{15}$ including the examination of CSF and brain microdialysate and the use of molecular imaging techniques such as PET. ${ }^{16}$ This lack of data is not surprising as these tools are resource intensive and so their application to a long list of potential molecular targets is difficult. Consequently, translation of the numerous findings of pathogenic mechanisms that have been identified in animal studies to therapies for human TBI remains a considerable challenge, both in terms of the number of candidate mechanisms that can be studied, and in determining whether changes in candidate molecular mediators are a cause or consequence of a 
disruption in autoregulation. A means of prioritizing the molecular mechanisms to be tested is needed to enable the most potentially rewarding candidates to be addressed with the sophisticated tools that we now have at our disposal.

Genome wide association studies (GWAS) in human disease provide an unbiased and cost-effective way to identify molecular mechanisms that are likely to be relevant to human disease biology. Such analyses could enable the selection of strong therapeutic candidates for investigation through exploratory approaches, or via examination of the effects of drug interventions that are targeted to the molecular pathways controlled by genes identified by GWAS. However, GWAS can be limited with regards to identification of rare genetic variants. Such rare variants can have a larger effect on phenotype and a more causal relationship to disease than common genetic variants and their associations.$^{17}$

This Review hopes to provide a platform for future genetic exploration into the molecular mechanisms involved in the regulation of cerebrovascular reactivity after TBI. Here, we overview some of the main theoretical mechanisms in cerebral blood flow (CBF) regulation, including myogenic, endothelial, neurotransmitter and metabolic theories. In addition, we introduce local inflammatory response, development of spreading cortical depression and autonomic dysfunction as additional potential drivers of impaired autoregulation after TBI. We then summarize genetic polymorphisms that have been associated with normal and abnormal vascular biology in a range of human disease, in relation to the outlined theories of CBF control and suggest additional drivers of dysfunction in $\mathrm{TBI}$, to enable prioritization of potential molecular targets in understanding and treating dysautoregulation following moderate and severe TBI.

\section{[H1] Mechanisms of cerebral autoregulation}

Cerebral autoregulation is defined as the ability of the cerebral vessels to maintain a constant CBF in the setting of variations in the pressure that drives blood flow - that is, mean arterial pressure and cerebral perfusion pressure (where cerebral perfusion pressure $=$ mean arterial pressure - intra-cranial pressure)

.$^{18}$ The mechanism of this regulation is believed to involve variations in cerebral vessel calibre (that is, internal diameter) in response to changes in the driving pressure. In 1959, Lassen provided the original description of the relationship between CBF and mean arterial pressure in humans - the cerebral autoregulatory curve - which was based on an amalgamation of CBF values from patients monitored 
during hemodynamic manipulations. ${ }^{18}$ This description, which has been validated in animal models and human studies, describes a mean arterial pressure range of 50-150 mm Hg within which physiologically normal cerebral autoregulation can take place and a relatively constant CBF can be maintained. Mean arterial pressure outside of this range exceeds the cerebral vessel's ability to regulate CBF and leads to deleterious consequences. Below the lower pressure limit of autoregulation, CBF cannot be maintained, leading to hypoperfusion, ischaemia and, potentially, infarct. The effects of this circumstance are exemplified by the increased morbidity and mortality observed in adults with TBI with perfusion pressure values below the individual's optimal target (determined via monitoring of autoregulation in that individual through the pressure reactivity index $(\mathrm{PRx})$ - a moving correlation between slow-wave vasogenic fluctuations in intra-cranial pressure and mean arterial pressure). ${ }^{19-21}$ Similarly, above the upper pressure limit of autoregulation, the cerebral vessels are unable to regulate flow, which leads to a state of hyperperfusion. This hyperperfusion can overwhelm the capillary bed due to elevated capillary filling pressures, which leads to cerebral oedema, impaired nutrient transport and, potentially, intracerebral haemorrhage. Findings in patients with TBI also support an association between poor outcome and a cerebral perfusion pressure value above an individual's optimal pressure.$^{21}$

Although the calibre of vessels involved in this cerebral autoregulatory process is debated, pre-capillary arterioles, which measure up to a few hundred microns in diameter, remain the most probable candidates. The exact mechanisms involved in the innate ability of cerebral vessels to regulate CBF through changes in tone and calibre are also debated. Current models of CBF control include myogenic, metabolic, neurotransmitter-mediated and endothelial-based mechanisms. ${ }^{22-25}$ The myogenic mechanism encompasses the direct mechanical reflex response of cerebral vessels to the variations in cerebral perfusion pressure experienced. ${ }^{26-29}$ As perfusion pressure rises, the stretch and shear stress experienced by the tunica media increases, leading to a vasoconstriction reflex, ensuring constant CBF. Conversely, low cerebral perfusion pressure leads to relaxation of the cerebral vessels in the context of decreased stretch of the tunica media. ${ }^{28}$ However, biochemical changes such as carbon dioxide or reactive oxygen species have also been observed to drive cerebrovascular responses in vitro and in vivo. $^{25,30-33}$ Metabolic mechanisms of CBF control involve byproducts of cerebral metabolism (such as lactate or reactive oxygen species during anaerobic metabolism) that can affect or dictate cerebral vessel calibre..$^{30,32-34}$ This process involves the control of capillary flow via capillary pericytes. ${ }^{35}$ In states of hypoperfusion, cerebral metabolism quickly shifts to anaerobic metabolism, resulting in the generation of lactate and other metabolic products ${ }^{30,32-34}$. These products are thought to generate 
changes in vessel calibre and promote restoration of adequate CBF. However, the production of sufficient concentrations of metabolic byproducts to affect cerebral vasoreactivity takes time; therefore, the metabolic theory of autoregulation does not explain the rapid temporal responses to changes in mean arterial pressure or cerebral perfusion pressure observed in cerebral vessels. The neurotransmitter theory of autoregulation suggests that all cerebrovascular reactivity is driven by direct neural input via the nervi vasorum. This mechanism would account for the rapidity of cerebral vascular response, but does not fully explain other biochemical responses. Finally, changes in perfusion pressure are also thought to dictate direct endothelial responses that regulate vessel calibre. Such endothelialbased mediators include NOS expression, eicosanoid release ${ }^{35,36}$ and endothelin response. ${ }^{36}$

Aside from these mechanisms, other aspects of the injury response might modulate cerebrovascular reactivity. For example, the inflammatory response seems to have a role in outcome after TBI and subarachnoid haemorrhage. ${ }^{37,38}$ Inflammatory responses to both primary and secondary brain injury might promote autoregulatory dysfunction. In addition, autonomic responses mediated by catecholamine action on cerebral vasculature might directly modulate vascular tone and regulate autoregulatory capacity after TBI. ${ }^{39}$ Other evidence suggests that abnormal cerebral electrophysiological responses to injury might modulate cerebrovascular reactivity. Spreading cortical depression has emerged as potential player in impaired cerebrovascular reactivity in animal models.$^{40}$ The presence, or increased frequency, of such electrophysiological patterns might also drive autoregulatory dysfunction after injury. Finally, disruption of solute and nutrient transport across the blood-brain barrier (BBB) might play a part in the potentiation of autoregulatory dysfunction.

The subsequent sections of this Review address the molecular and cellular mechanisms involved in each of these mechanisms, and highlight key genetic polymorphisms that could link them to human disease (FIG. 1).

\section{[H1] Myogenic mechanisms}

The myogenic mechanistic theory for cerebral autoregulatory response proposes that the tunica media undergoes stretch-mediated or shear-stress-mediated responses to changes in perfusion pressure or blood flow. A natural next step in exploring this theory is to investigate the involvement of potential 
mechanisms affecting smooth muscle tone. Table 1 provides a list of candidate SNPs that are potentially involved in the cerebrovascular myogenic response, which warrant further.

[H2] Calcium signalling. Calcium channel-dependent contraction and relaxation in smooth muscle play an important part in cerebrovascular responsiveness. As such, SNPs in calcium channels have the potential to dictate the degree of cerebrovascular responsiveness in both the healthy and diseased state. Mutations in voltage-dependent calcium channel subunits can lead to altered smooth muscle response to changes in flow and calcium influx. The regulation of calcium-activated potassium channel and transient receptor potential (TRP) channel function might also lead to calcium-mediated changes in cerebrovascular tone. ${ }^{41}$ Studies in fawn-hooded hypertensive rats suggest that dual specificity protein phosphatase 5 (DUSP5) is a main mediator of renal and middle cerebral artery tone via inactivation of mitogen-activated protein kinase (MAPK) activity, which leads to decreased regulation of downstream large calcium-activated potassium channels and TRPs. ${ }^{41,42}$ Cerebral autoregulatory capacity was preserved in Dusp5 knock-out rats, as tested via cortical laser Doppler flowmetry during hyperventilatory and cerebral perfusion pressure challenges, suggesting that the role of Dusp 5 in CBF control is still unclear. Mutations within a particular family of DUSPs (those linked to activity of MAPK or other phosphatases) might be predicted to lead to autoregulatory dysfunction in humans, but no DUSP mutations related to cerebral vessel function in humans have been reported to date. However, several well-documented polymorphisms occur in the TRP channel proteins and have been implicated in disease states that involve abnormal cerebrovascular biology. ${ }^{43}$ SNPs in the TRP type M (TRPM) channel have been linked to diseases associated with cerebrovascular dysfunction, including migraine. ${ }^{43}$ Furthermore, TRPM calcium channels are downstream targets for glutamate-mediated N-methyl-D-aspartate (NMDA) receptor activation, a pathway known to be upregulated during neuropathological states. TRPM2 has been postulated as a potential target for the downstream effects of glutamate-mediated excitotoxicity (see section on neurotransmitters and cerebral autoregulatory response for further discussion of glutamate-mediated excitotoxicity in cerebral autoregulation) ${ }^{44}$. TRPM4, a calcium-activated and calcium-modulating channel that influences intracellular and extracellular concentrations of calcium, also might modulate vascular tone, although this activity has yet to be definitively demonstrated. TRPM8, which is known to play a prominent part in trigeminal-mediated thermoreception, has recently been indicated as a potential player in cerebral vasoconstrictive responses, and is also known to be regulated by voltage gated glutamate channels (VGLUT) within the brain. ${ }^{43,45,46}$ Voltage-dependent 
calcium channel, DUSP and TRPM SNPs, therefore, warrant exploration in the context of autoregulatory capacity in TBI.

[H2] Angiotensin. In addition to calcium-mediated mechanisms, vascular myogenic responses are also modulated by the angiotensin system. Mutations in genes encoding angiotensin-converting enzyme (ACE) and the angiotensin II receptor have been linked to the development of delayed ischaemic neurological deficits in subarachnoid haemorrhage. ${ }^{47,48}$ The type 2 angiotensin II receptor (AGTR2) A/C SNP (rs11091046) has been linked to the development of aneurysmal subarachnoid haemorrhage. Both the recessive AGTR2 A/C allele SNP (OR 4.70, 95\% $\mathrm{Cl}$ 1.43-15.4) and the recessive effect of the insertion allele of the ACE rs4340 insertion-deletion polymorphism (also known as rs4646994; OR 3.63, 95\% Cl 1.04-12.7) were linked to an increased risk of symptomatic cerebral vasospasm. ${ }^{47}$ Similarly, another study demonstrated a link between impaired reactivity to $\mathrm{CO}_{2}$, measured using TCD ultrasonography, and the angiotensinogen (AGT) rs699 CC genotype ( $P=0.00028)$ in healthy elderly volunteers. ${ }^{49}$ In addition, research in patients with TBI supports the link between ACE rs7221780 (OR 2.67, 95\% Cl: 1.25 - 5.72) and rs8066276 (OR 3.82, 95\% $\mathrm{Cl}: 1.80-8.13$ ) and global patient outcome, with the minor alleles linked to a worse 6-month Glasgow Outcome Scale (GOS) score. ${ }^{50}$ Furthermore, the ACE rs 4646994 insertion-deletion polymorphism has been linked to worse cognitive and motor outcome in $D$ allele carriers at 1 month after TBI $(P=0.001) .{ }^{51}$ Given these results, polymorphisms involving ACE, AGTR2 and the renin-angiotensin system could have an important role in the cerebral myogenic response and autoregulatory capacity, and might alter patient functional outcome in TBI.

\section{[H1] Endothelial Mechanisms}

Changes in intraluminal perfusion pressure or shear stress produced by changes in blood flow can lead to alterations in endothelial expression of vasoactive mediators. Mediators of cerebrovascular tone that are expressed in the endothelium include, but are not limited to: nitric oxide synthase (NOS), adenosine receptors, endothelin and eicosanoids. Table 2 displays the SNPs that are potentially linked to endothelial mediation of vascular tone and cerebral autoregulation.

[H2] Nitric oxide synthase. Several isoforms of NOS are expressed, including endothelial (NOS3), inducible (NOS2) and neuronal-specific variants (NOS1), which each affect vascular tone in different organ systems throughout the body. NOS activity leads to the production of nitric oxide, a potent 
vasodilator, and promotes endothelial-mediated vasodilation during states of hypoxia and ischaemia through the generation of cyclic guanosine monophosphate and decreased levels of intracellular calcium. ${ }^{52}$ NOS3 activity in particular is intimately intertwined with endothelial adenosine, ${ }^{53}$ appearing to modulate cerebral vascular responses in experimental subarachnoid haemorrhage (via NOS3 and endothelial adenosine responses in the development of vasospasm). Furthermore, NOS3 displays close association with endothelin function, as exemplified in the development of preterm infant intraventricular haemorrhage (via the association of NOS3 and endothelin-1 polymorphisms). ${ }^{54}$ Dysfunctional NOS activity can lead to the development or potentiation of pathological states. A variety of SNPs in genes that regulate NOS and other downstream mediators in the nitric oxide pathway have been linked to vascular pathology. In patients with severe TBI, a NOS3-786 C/C loss-of-function genotype has been linked to increased mortality $(P=0.022)$ and reduced cortical CBF velocity $(P=0.015)$, as defined by TCD-based assessments of the middle cerebral artery, internal carotid artery, anterior cerebral artery and posterior cerebral artery $\left(p<0.001\right.$ for all). ${ }^{55}$ Furthermore, autoregulatory function, measured using the transient hyperaemic response following brief carotid compression, is impaired in the same cohort $(P=0.010)$. Similarly, the NOS3 $894 \mathrm{G} / \mathrm{T}$ and T/T loss-of-function genotypes displayed dramatic differences in cerebrovascular $\mathrm{CO}_{2}$ reactivity, tested using $T C D$, with a decrease in CBF velocity in the G/T genotype and an increase in CBF velocity in the T/T genotype $(P=0.005) .{ }^{55}$ Additionally, data from patients with subarachnoid haemorrhage suggest that NOS activity is linked to the development of cerebral vasospasm and delayed ischaemic neurological deficit, with reduced NOS3 and increased NOS2 activity linked to worse spasm. Patients harbouring the rs2070744 C allele of NOS3 have an increased risk of cerebral vasospasm after aneurysmal subarachnoid haemorrhage (OR 2.936, $95 \% \mathrm{Cl} 1.048-8.226, P=0.040) .{ }^{56,57}$ Finally, possible links have been found between a variety of NOS2 and NOS3 polymorphisms and migraine. ${ }^{58} \mathrm{All}$ of these NOS polymorphisms deserve further exploration with regards to their relationship to autoregulatory function, both in healthy states and in diseased states such as TBI.

[H2] Adenosine receptors. The endothelial adenosine receptors A1 and A2A are also known to play a part in the regulation of cerebrovascular tone through downstream effects that include inhibition of adenylate cyclase, reduction in cyclic adenosine monophosphate and inhibition of N-type, P-type and Qtype calcium channels. ${ }^{53,59}$ Adenosine-mediated agonism of these receptors is triggered during hypoxia, ischaemia or inflammation, and might interact with NOS-mediated responses. ${ }^{59}$ Results from animal models suggest that agonism of adenosine $A 1$ and $A 2 A$ receptors might reduce the incidence of cerebral 
vasospasm in experimental subarachnoid haemorrhage ${ }^{53,59}$. Although no link between adenosine receptor polymorphisms and cerebrovascular response in humans has been reported to date, the effect of these polymorphisms on cerebral autoregulatory responses in TBI deserves exploration.

[H2] Endothelin receptors. Endothelin signalling via G-protein-coupled endothelin receptors $\left(E_{A}, E_{B}\right.$, $\mathrm{ET}_{\mathrm{B} 2}$ and $\mathrm{ET}_{\mathrm{C}}$ ) can modulate NOS3-mediated vascular responses through phosphorylation of NOS3 by phosphatidylinositol-3-kinase.${ }^{54}$ Polymorphisms in EDN1, encoding endothelin 1, have been linked to a variety of vascular diseases, including hypertension, ${ }^{60}$ coronary artery disease, ${ }^{61}$ migraine ${ }^{58}$ and cervical artery dissection. ${ }^{61}$ An association has been suggested between the rs2070699 $(P=0.03)$ and rs1626492 $(P=0.02)$ polymorphisms in EDN1, and the development of migraine with aura. ${ }^{58}$ Furthermore, SNPs in genes encoding endothelin receptors - EDNRA -231 AA and EDNRB rs9544636 - have been linked to migraines, ${ }^{58}$ and link has also been suggested between EDNRA rs5335 SNP G allele carrier status and subarachnoid haemorrhage related vasospasm (OR 4.62, 95\% $\mathrm{Cl} 1.31-16.26, P=0.017$ ). ${ }^{57}$ However, these SNPs require exploration in the setting of autoregulatory dysfunction in the TBI population.

[H2] Eicosanoid and prostaglandin biology. The association of polymorphisms in genes involved in eicosanoid and prostaglandin biology with cardiovascular and cerebrovascular disease has been well documented. The main mechanisms thought to be involved in this relationship include platelet dysfunction, modulation of vascular tone through prostaglandin G-protein-coupled receptors and endothelial damage. Furthermore, systemic vasoconstriction by prostaglandin 12 seems to be mediated through endothelial serotonergic responses (an association that is addressed in more detail in the next section). ${ }^{62,63}$ Consequently, a link might exist between such SNPs and cerebral autoregulatory function in $\mathrm{TBI}$, although data supporting this association currently are lacking.

\section{[H1] Neurotransmitter Mechanisms}

Neurotransmitters have a key role in neuronal action potential propagation, intracellular communication and regulation of cellular homeostasis within the brain. Naturally, some of these transmitters directly influence the cerebrovascular response and autoregulatory capacity. Some potential key players in neurotransmitter function and cerebrovascular reactivity include catechol-Omethyltransferase (COMT), brain-derived neurotrophic factor (BDNF), calcitonin-related polypeptide alpha (CALCA), 5-hydroxytryptamine (5-HT; serotonin) receptors, monoamine oxidase (MAO) and VGLUT 
channels. Table 3 lists the SNPs in genes involved in neurotransmitter signalling that might affect autoregulatory function. The effects of these SNPs on outcome have been attributed largely to alteration of neurotransmitter tone, which affects cognitive processing ${ }^{14}$. However, the effects of these neurotransmitters on vasoregulation could also be an important mechanistic link between genetic polymorphism and outcome.

[H2] Catechol-O-methyltransferase. COMT degrades catecholamine-based neurotransmitters and pharmacologic agents through methylation of the catechol group present within these compounds. Inactivation of endogenous and exogenous catecholamine-based agents leads to decreased levels of dopamine, norepinephrine and epinephrine, all of which have direct cerebral vasoactive properties. Polymorphisms in COMT have been associated with migraine and with decreased response to migraine pharmacotherapy. ${ }^{58}$ COMT polymorphisms have been shown to affect global, behavioural and neuropsychiatric patient outcomes after TBI. ${ }^{64-66}$ The COMT Val158Met SNP is the most well documented of these polymorphisms, with presence of the Met allele associated with improved GOS scores at 6 months $(2.87,95 \% \mathrm{Cl} 1.20-6.86)^{64}$ and improved 1-2-month Wisconsin Card Sorting Test results. ${ }^{66}$ These results suggest a link between COMT polymorphisms and cerebrovascular responses in TBI. However, no data are currently available that directly demonstrate this link.

[H2] Brain-derived neurotrophic factor. BDNF is a messenger molecule that promotes synaptic plasticity and neuronal survival. ${ }^{67}$ Furthermore, BDNF has been linked to cerebrovascular and neuroinflammatory responses after injury. ${ }^{68,69}$ Studies in patients with TBI support a link between BDNF SNPs and global, behavioural and neuropsychiatric outcomes. ${ }^{14} \mathrm{An}$ increased risk of mortality at 7 days after TBI was observed in carriers of the BDNF rs6265 Val66Met allele and rs7124442 C allele $(P=0.0286) .^{70}$ Furthermore, 1-year survival was increased in individuals with BDNF rs6265 Val/Val and rs7124442 T/T genotypes $(P=0.006)$. Similarly, other studies have linked the BDNF rs6265 Met allele carrier status to worsened neuropsychiatric performance after TBI. ${ }^{71-73}$ Preliminary animal data also suggests a role for the BDNF Val66Met polymorphism in enhanced glutamatergic transmission, ${ }^{74}$ which could play a part in glutamate mediated excitotoxicity in the setting of injury. No direct link between polymorphisms in BDNF and cerebrovascular response in TBI has been made to date. However, BDNF rs6265 Val allele carrier status has been linked to reversible cerebral vasoconstriction syndrome $(P<0.001)$, a cerebral condition characterized by cerebral vasospasm. ${ }^{68}$ In addition to the direct effect of BDNF SNPs on neurological disease, polymorphisms in BDNF and CALCA might also modulate one another. ${ }^{58,75}$ CALCA 
has a direct vasodilatory effect on cerebral vessels, and is believed to be responsible for neurogenic inflammation. The CALCA rs1553005 GC genotype has been linked to migraines, and preliminary data suggests an interaction with the BDNF rs2049046 AT genotype (OR 1.88, 95\% Cl 1.2-2.93, $P=0.005$ ), with both genotypes being higher in migraineurs. ${ }^{75}$ However no formal studies have examined the association between CALCA and outcome or cerebrovascular response in patients with TBI, so the question of whether BDNF and CALCA SNPs have a substantial effect on autoregulatory capacity remains.

[H2] 5-hydroxytryptamine. Serotonin leads to vasoconstriction through upregulation of prostaglandin 12 function and inhibition of NOS3. This effect seems to be mediated through the endothelial 5-HT receptors 1 and $2^{62,63}$. Polymorphisms in genes encoding 5-HT receptor $1 \mathrm{~A}(H T R 1 A), 5-H T$ receptor $1 \mathrm{~B}$ $(H T R 1 B$,$) and 5-HT receptor 2A (HTR2A) are linked to the development of migraine. { }^{58}$ In addition, SNPs in SLC6A4, encoding the sodium-dependent serotonin transporter have been linked to migraines. ${ }^{58}$ Furthermore, a link has been found between the SLC6A4 rs25531 G/G SNP and depression after TBI, 14,76 as assessed by patient health questionnaire at 12 months (OR 3.34, 95\% $\mathrm{Cl} 1.135-9.849, \mathrm{p}=0.029$ for G/G genotype). However, at present, no direct link between SNPs in 5-HT-related genes and cerebrovascular response in patients with TBI has been found. Thus, further exploration of these SNPs and their association with cerebrovascular reactivity in TBI is warranted.

[H2] Monoamine oxidase. MAO is an enzyme involved in the metabolism of catecholamine neurotransmitters, and some subtypes of MAO also display an affinity for 5-HT. A 30 base-pair variable number tandem repeat (VNTR) in MAO type A (MAOA) has been associated with migraine with aura in men $(P=0.043) .{ }^{58}$ Furthermore, in individuals with prefrontal cortical lesions after TBI, a link has been found between 3.5 or 4 repeat MAOA VNTR alleles, which have high transcriptional activity, and the development of increased aggression, as assessed using the neuropsychiatric inventory agitation/aggression subscale. ${ }^{14,77}$ Aside from these findings, research regarding MAO SNPs and cerebrovascular response remains preliminary, and further exploration is required within the population of patients with TBI.

[H2] Voltage-gated glutamate channels. Glutamate is one of the main excitatory neurotransmitters within the CNS, and delivers many of its effects through engagement with a number of receptors (including NMDA, $\alpha$-amino-3-hydroxy-5-methyl-4-isoxazolepropionic acid (AMPA) and metabotropic 
receptors), some of which stimulate changes in intracellular calcium. Alterations in glutamate biology have been linked to numerous diseases, including refractory seizures and neuropsychiatric conditions. Upregulation of glutamate neurotransmission and consequent excitotoxic cell injury has been well documented in the setting of ischaemia and injury. ${ }^{78}$ NMDA receptor-mediated increases in intracellular calcium levels represent a key mechanism in this context. Furthermore, glutamate and its mediators have been implicated in spreading cortical depression, a electrophysiological phenomenon associated with cerebrovascular dysfunction ). ${ }^{40,79}$ Further information on spreading cortical depression and some polymorphisms that might be involved can be found in Supplementary Box 1. In addition, elevated extracellular glutamate concentrations were found to be associated with worse global outcome and impaired autoregulatory capacity in patients with moderate to severe TBI, as measured by PRx ${ }^{80,81} \mathrm{TBI}$ outcome and vascular biology might also be affected by genetic variation in other parts of the glutamatergic neurotransmission pathway - for instance, through variations that result in downregulation of the glial high-affinity glutamate transporter solute carrier family 1 member 2 (SLC1A2), which is responsible for regulating levels of glutamate in the CNS. ${ }^{82}$ Studies have suggested that polymorphisms in VGLUT channels modulate TRPM8-mediated calcium channel function (as described in the previous section on myogenic mechanisms). In addition, individuals who carry the rs74174284 G allele in SLC17A7 (also known as VGLUT1) have delayed recovery after mild TBI ( $P=$ 0.018), and the C allele is associated with worse motor ImPACT (Immediate Post-Concussion Assessment and Cognitive Test) scores at patient admission $(P=0.012) .{ }^{83}$ Polymorphisms in GRIN2A, which encodes an NMDA receptor subunit, have been linked to altered outcome in patients with mild TBI, with carriers of a long GT VNTR ( $\geq 25$ repeats) having delayed recovery $(P=0.0433) .{ }^{84}$ In addition, the CACNA1A Ser218Lys SNP was linked to cerebral oedema in a small series of patients with mild TBI, potentially mediated through neuronal calcium influx and increased glutamate mediated excitotoxocity. ${ }^{85}$ In addition to TBI, the SLC1A2 A to C SNP (rs3794087) has been linked to migraines and cluster headaches. ${ }^{58}$ Furthermore, the CACNB2 rs7076100 SNP seems to be related to an increased risk of migraine, which is again thought to be secondary to increased calcium triggering glutamate excitotoxicity. ${ }^{58}$ The direct effect that glutamate and its downstream effects have on cerebral autoregulation remain unknown; however, the studies discussed here support the consideration of glutamate-related genes in future TBI genomic studies related to autoregulatory capacity.

\section{[H1] Metabolic Mechanisms}


The metabolic theory of cerebral autoregulatory response focuses on the downstream effects of metabolic byproducts on cerebral vascular tone and response. Numerous aspects of cerebral metabolism are disrupted during TBI. These alterations include a switch to anaerobic metabolism and impairment of BBB nutrient transport, both of which might affect cerebrovascular reactivity. Table 4 lists metabolism-related SNPs that might participate in autoregulatory function.

[H2] Anaerobic metabolism. The switch from aerobic to anaerobic metabolism in cerebral injury is facilitated by regional, and potentially global, impairment to cerebral blood flow and nutrient delivery. Findings from animal studies show that lactate - one of the main metabolic byproducts of anaerobic glucose metabolism - directly inhibits arterial smooth muscle contraction via inhibition of calcium influx across the sarcolemma. ${ }^{86}$ Thus, impaired autoregulation might lead anaerobic metabolism and lactate production, and lactate accumulation might in turn drive worsening autoregulatory capacity. Polymorphisms within the mitochondrial DNA might play an important part in aberrant glucose metabolism, lactate production and lactate handling, owing to the vital role of this organelle in glucose metabolism. Furthermore, mitochondrial respiratory chain dysfunction in cerebrovascular endothelial cells was found to result in compromised BBB permeability in a mouse model of stroke, which could promote autoregulatory dysfunction. ${ }^{87}$ Thus, mitochondrial polymorphisms might have important role in a pathway that can indirectly potentiate autoregulatory dysfunction in TBI.

An increased lactate:pyruvate ratio, as assessed by cerebral microdialysis, was associated with impaired cerebrovascular reactivity, as measured by PRx, in patients with TBI. ${ }^{80,81} \mathrm{PRx}$ is one of the few continuous measures of cerebral autoregulatory capacity that has been validated against Lassen's cerebral autoregulatory curve in animal models, ${ }^{88}$ so the association between lactate:pyruvate ratio and PRx is an important one. Impaired PRx, and thus autoregulatory capacity, might be presumed to lead to impaired CBF and nutrient delivery. Thus, in the setting of autoregulatory dysfunction, anaerobic metabolism would dominate and lead to an elevation in lactate, and subsequently to an elevation in the lactate:pyruvate ratio. However, lactate might also affect autoregulation in other ways. In a cohort of patients with TBI who were heterogeneous with regards to severity, mitochondrial DNA haplogroup $\mathrm{K}$ was linked to a reduced risk on the GOS of 4 or 5 at 6 months (OR $0.21,95 \% \mathrm{Cl} 0.38-1.82$ ). ${ }^{89}$ Similarly, the mitochondrial DNA-10398G polymorphisms seem to lead to reduced disability at 6 and 12 months after severe TBI ( $p=0.02)$, as assessed by GOS. ${ }^{90}$ These differences in outcome related to mitochondrial DNA haplotypes and polymorphisms might be attributed to the differences in aerobic and anaerobic 
metabolism associated with these genetic changes. These findings are preliminary and further exploration is required.

[H2] Blood-brain barrier dysfunction. Transport of nutrients and waste products across the BBB is frequently impaired in the setting of cerebral injury. The BBB is composed of astrocytic foot processes (separated by gap junctions), basement membrane and endothelial cells (separated by tight junctions). Each aspect of the BBB is involved in the transport process. A variety of channels, intracellular junctions and active or passive transmembrane processes are involved solute transport, both of nutrients and of waste products. Consequently, polymorphisms in BBB transport processes might facilitate early transition to anaerobic metabolism in the setting of injury, and subsequently promote autoregulatory failure. The ATP binding cassette $(A B C)$, and its various isoforms, regulate solute transport across the BBB. In adults with TBI, the $A B C C 1$ GG SNP (OR $0.73,95 \% \mathrm{Cl} 0.55-0.98, P=0.04$ for poor outcome) and $A B C B 1 \mathrm{TT}$ SNP (OR 0.71, 95\% Cl 0.55-0.92, $\mathrm{p}=0.01$ ) show a trend towards improved GOS at 6 months (controlling for Glasgow coma score, age, sex, and injury severity score). ${ }^{91}$ In addition, SNPs in a variety of different $A B C s$ are linked to elevated intra-cranial pressure and CT-based cerebral oedema in patients with moderate or severe TBI. ${ }^{92}$

The aquaporin 4 (AQP4) channel is the primary astrocytic channel responsible for water homeostasis across the BBB. AQP4 is known to be impaired by lactate accumulation. The AQP4 rs3763043 TT genotype has been linked to worse 6 month GOS (OR 5.15, 95\% Cl 1.60-16.5, $P=0.0006$ ), whereas AQP4 rs3875089 C allele carrier status was associated with improved outcomes (OR 0.18, 95\% Cl 0.07-0.50, $p=0.0009$ for poor outcome).$^{93}$ Finally, the matrix metalloproteinases (MMP), a family of endopeptidases responsible for degradation of various extracellular proteins, are also known to affect BBB integrity in the setting of injury. Cerebral microdialysis studies in TBI have shown an increase in the levels of MMP7, MMP8 and MMP9 (amongst other MMPs) in cerebral extracellular fluid after injury, and some data also suggest a link between certain MMPs and patient outcome. ${ }^{94,95}$ Although no data is available that directly links MMP SNPs to TBI pathogenesis, data in the field of migraine supports an association between SNPs in MMP2, MMP3 and MMP9 with the increased risk of migraine. ${ }^{58}$

\section{[H1] Other polymorphisms of interest}


Other genetic polymorphisms might affect cerebral autoregulatory function after injury, but data in these areas are limited. Polymorphisms related to the inflammatory response, ${ }^{96-101}$ autonomic response ${ }^{102-105}$ or spreading cortical depression ${ }^{40,106}$ after TBI all have the potential to affect cerebrovascular reactivity. In addition, some systemic vascular and cardiovascular polymorphisms deserve consideration in future studies assessing the link between genetic polymorphisms and autoregulatory dysfunction. Such polymorphisms include those associated with increased vascular tone in systemic hypertension and coronary vasospasm, as well as those linked to NOS pathways, ${ }^{60,107,108}$ the renin-angiotensin system, ${ }^{60,107}$ adenosine receptors ${ }^{109}$ and the eicosanoid pathway. ${ }^{110} \mathrm{~A}$ brief overview of these additional polymorphisms is provided in Supplementary Box 1.

\section{[H1] Limitations and considerations}

Current knowledge of genetics in TBI, including of SNPs related to cerebral autoregulation, is far from complete. To date, only a small selection of specific SNPs have been investigated for their relation to global or neuropsychiatric outcomes in adult TBI. ${ }^{14}$ Furthermore, the basic biology of the mechanisms involved in CBF control (including myogenic, endothelial, neurotransmitter-based and metabolic mechanisms) is incompletely understood. ${ }^{22,23,25}$ Our Review provides an initial framework for exploring this pathophysiological landscape, which we expect to evolve as new data emerge.

Some of the SNPs discussed in this review emerged from outside of the study of TBI. Many other cerebral conditions are linked to vascular dysfunction (including migraine, stroke and subarachnoid haemorrhage-related vasospasm), and it is important to consider the SNPs that have been linked to these other pathologies, as they might be involved in CBF regulation and the autoregulation response after TBI. We also make passing reference to SNPs linked to cardiovascular (such as coronary vasospasm) and systemic vascular diseases (such as essential hypertension), which might play a part in cerebral vessel responses. Despite the differences between these diseases and TBI, these SNPs deserve consideration on account of their role in cerebral autoregulatory failure.

Many of the mechanisms that we suggest here are based on preliminary findings and will require further experimental evidence and validation. To date, the majority of studies on individual SNPs involved in autoregulatory dysfunction are single centre and, mainly, single study. ${ }^{14}$ The statistical significance of some of the associations described were weak (that is, p-values were close to 0.05 ), which limits the strength of the conclusions that can be made regarding the potential association between various genes 
or SNPs and cerebrovascular function. Many of the studies considered in this article had small sample sizes (that is, fewer than 500 patients), which is a common issue with many studies of TBI and is likely to have affected the statistical significance, or lack thereof, of the SNPs described. As such, these previous genetic studies should be considered exploratory, rather than definitive. However, the SNPs featured in this Review provide a logical basis for future study and elucidation of molecular pathways involved in cerebral autoregulatory dysfunction after TBI. To identify any potential false positive associations, these SNPs will require investigation with large sample sizes and multi-centre collaboration to obtain definitive evidence of their association, or lack thereof. Such large studies will require substantial funding and longitudinal recruitment of patients to overcome this limitation, particularly if evaluated via GWAS, given the sample size and power requirements of such studies. ${ }^{14,111-114}$

The complexity of TBI care also must not be underestimated. The heterogeneity in primary injury patterns, secondary injury mechanisms and intensive care unit therapies administered all affect cerebral autoregulation, ${ }^{115-117}$ and any monitoring parameters related to this process. Importantly, some of these injury-related mechanisms might operate only in close vicinity to focal lesions, whereas other effects might be global. ${ }^{115,118,119}$ Age and sex are also well known to affect response to therapies in TBI and cerebral autoregulatory response to injury, ${ }^{7,120-124}$ and require acknowledgment as confounding factors. In addition, whether the same mechanisms are involved in impaired cerebrovascular reactivity in both mild $\mathrm{TBI}^{125-127}$ and moderate to severe TBI is unknown.$^{6-9}$ Future studies will need to be carefully planned to account for such heterogeneity, further requiring large samples sizes and multi-centre collaboration.

Data from multi-centre consortiums in TBI research, such as TRACK-TBI ${ }^{128}$ and CENTER-TBI ${ }^{129}$ provide one solution for the accumulation of the sample sizes needed for such analyses. The highly granular data needed to fully explore the association between genetic variation and autoregulatory dysfunction might be available in only a subset of such cohorts. However, in a second stage analysis, the accumulation of samples sizes from these and other large consortia will enable us to test the effect of genes on patient outcomes in large sample sizes, even if detailed autoregulatory phenotypes are not fully documented in these patients.

The techniques used to characterize the phenotype of autoregulatory dysfunction also require optimization. Currently, the most commonly used method consists of continuously updated moving 
correlation coefficients between slow-wave vasogenic fluctuations in intra-cranial pressure and mean arterial pressure. ${ }^{9}$ In TBI, PRx is most commonly used among these indices ${ }^{6,9,130}$ and has been validated to measure autoregulation in animal models. ${ }^{88,131,132}$ However, PRx is a global representative of autoregulatory capacity, despite it being based on a focal intra-cranial pressure measurement. ${ }^{6}$ We know that autoregulatory responses to injury can be heterogeneous, with hemispheric or regional differences.${ }^{118-120}$ Consequently, future studies might benefit from considering a multi-modal approach to the measurement of cerebral autoregulation. Such assessment could consist of continuous regional autoregulatory measures, such as those derived from near-infrared spectroscopy ${ }^{9}$ or robotic TCD. ${ }^{133}$ This approach would enable continuous assessment of regional cerebral autoregulation after TBI and its association with different genetic polymorphisms. Use of near-infrared spectroscopy and TCD technology, in combination with non-invasive continuous blood pressure monitoring, enables cerebral autoregulation to be continuously and non-invasively monitored during follow-up or in an outpatient setting after invasive monitoring devices have been discontinued. ${ }^{134,135}$ These approaches have not been used previously, and might shed light on the association between long-term morbidity after TBI and ongoing cerebral autoregulatory dysfunction. In this context, the use of advanced imaging - such as functional MRI with arterial spin labelling (ASL) or blood oxygen level dependent (BOLD) contrast - has been pioneered in patients with mild TBI or concussion. ${ }^{125-127}$ These approaches promise not only detailed spatial assessment of regional vascular regulation in the chronic phase, but also exploration of regional effects in the acute phase of severe injury. Furthermore, incorporation of cerebral microdialysis ${ }^{81,136}$ and monitoring of oxygen levels ${ }^{137}$ in brain tissue of those with moderate to severe TBI could enable the exploration of links between abnormal vascular function and tissue biochemistry in the context of genetic variation. Such comprehensive approaches on large and complex data sets would incorporate various data structures (such as time series and ordinal categorical data) and might require application of machine learning or deep learning techniques to aid with handling such large data sets, but could yield important insights.

\section{[H1] Future directions}

The data presented here provide plausible evidence that genetic polymorphisms influence vascular biology after TBI and affect patient outcomes. Exploration is now needed to determine the best way to test the hypotheses posed in this Review in the context of TBI. 
The hypothesis that the polymorphisms highlighted in this Review have a role in impaired cerebral autoregulation in TBI might be addressed most robustly by GWAS. However, although a positive result from such an analysis is robust, false negatives are highly likely as they take no account of prior knowledge of the molecular mechanisms involved in CBF control that we have provided from the analysis of vascular biology in this article, and both patient and injury heterogeneity. We believe that the scientific questions that emerge from this Review could be better answered by using Bayesian approaches that do take account of these priors. ${ }^{138}$ Other approaches might be needed to investigate the effects of rare variants (with a minor allele frequency $<1 \%$ ). ${ }^{139}$ These variants might have a substantial biological effect, but remain undetected by GWAS in the sample sizes currently available for TBI ( 10,000 participants when aggregated across multiple studies). Targeted approaches that use selected polymorphism testing to confirm initial GWAS hits might be possible (as has been the case for pharmacogenomics of antiplatelet agents ${ }^{140}$ ) but will require polymorphism targets for validation, which need to emerge from initial GWAS or Bayesian analyses.

The availability of parametric phenotypes confers statistical power that can enable inferences to be made with modest sample sizes with whole genome sequencing. ${ }^{141}$ Consequently, development of optimal phenotypic metrics are needed for genetic studies of autoregulation in. We have provided suggestions throughout the article regarding phenotypes of interest - such as autoregulatory efficiency, measured via continuously updated indices of cerebrovascular reactivity that are based on a variety of multi-modal invasive and non-invasive methods of cerebral monitoring. ${ }^{4,5}$ These quantitatively measured phenotypes enable focused studies of gene subsets that are informed by initial GWAS and Bayesian analysis.

Many of the large collated datasets that enable such analysis are currently confined to patients with moderate to severe $\mathrm{TBI}$, and use invasive monitoring to provide the inputs for analysis of autoregulatory efficiency. Although some vascular behaviour might be dominated by the severity of TBI, variations in host response might also modulate the pathophysiological phenotype of TBI across the severity spectrum. Consequently, it is important to explore techniques that can be used to characterize autoregulation in mild forms of injury - such as functional MRI with arterial spin labelling ${ }^{127}$ or BOLD contrast ${ }^{125,126}$, and continuous non-invasive blood pressure monitoring coupled with TCD ultrasonography $y^{9,133,135,142}$ or near-infrared spectroscopy ${ }^{9,134,143}$. Furthermore, it is important to study the 
association of long-term regional autoregulatory capacity with clinical outcomes in patients with TBI at follow-up.

\section{Conclusions}

Impaired cerebral autoregulation after TBI leads to substantial morbidity and mortality. Development of therapies to prevent and treat dysautoregulation in TBI requires exploration of genetic predisposition towards altered autoregulation. We have highlighted some candidate SNPs that might play a part in cerebral autoregulation. Polymorphisms involved in the myogenic, endothelial, neurotransmitter-based and metabolic cerebrovascular response provide key targets for investigation. Furthermore, SNPs related to some potential drivers of autoregulatory failure (including inflammatory response, autonomic response and spreading cortical depression) also merit exploration.

\section{Competing Interests statement}

P.S. and M.C. have financial interests in a part of licensing fee for ICM+ software (Cambridge Enterprise Ltd, UK). D.K.M. has consultancy agreements and/or research collaborations with GlaxoSmithKline, Ornim Medical, Shire Medical, Calico, Pfizer, Pressura, Glide Pharma, and NeuroTraumaSciences.

\section{Acknowledgments}

This work was made possible through salary support through the Cambridge Commonwealth Trust Scholarship, the Royal College of Surgeons of Canada - Harry S. Morton Travelling Fellowship in Surgery and the University of Manitoba Clinician Investigator Program. This work was also supported by National Institute for Healthcare Research (NIHR, UK) through the Acute Brain Injury and Repair theme of the Cambridge NIHR Biomedical Research Centre and an NIHR Senior Investigator Award to D.K.M. E.P.T. received funding support from Swedish Society of Medicine (Grant no. SLS-587221). Authors were also supported by a European Union Framework Program 7 grant (CENTER-TBI; Grant Agreement No. 602150).

\section{Author contributions}


All authors reviewed and edited the manuscript before submission. F.A.Z, E.T., J.D., P.J.H. and D.K.M. contributed substantially to the discussion of content. F.A.Z. researched data for the article and wrote the manuscript. 


\section{References:}

1. Maas, A. I. R. \& Menon, D. K. Integrated approaches to paediatric neurocritical care in traumatic brain injury. Lancet Neurol. 12, 26-28 (2013).

2. Feigin, V. L. et al. Incidence of traumatic brain injury in New Zealand: a population-based study. Lancet Neurol. 12, 53-64 (2013).

3. Gardner, A. J. \& Zafonte, R. Neuroepidemiology of traumatic brain injury. Handb. Clin. Neurol. 138, 207-223 (2016).

4. Rosenfeld, J. V. et al. Early management of severe traumatic brain injury. Lancet Lond. Engl. 380, 1088-1098 (2012).

5. Carney, N. et al. Guidelines for the Management of Severe Traumatic Brain Injury, Fourth Edition. Neurosurgery 80, 6-15 (2017).

6. Czosnyka, M. et al. Continuous assessment of the cerebral vasomotor reactivity in head injury. Neurosurgery 41, 11-17; discussion 17-19 (1997).

7. Zeiler, F. A. et al. Critical Thresholds of ICP Derived Continuous Cerebrovascular Reactivity Indices for outcome prediction in Non-Craniectomized TBI Patients: PRx, PAx and RAC. J. Neurotrauma 35, 1107-1115 (2018).

8. Sorrentino, E. et al. Critical thresholds for cerebrovascular reactivity after traumatic brain injury. Neurocrit. Care 16, 258-266 (2012).

9. Zeiler, F. A. et al. Pressure Autoregulation Measurement Techniques in Adult Traumatic Brain Injury, Part II: A Scoping Review of Continuous Methods. J. Neurotrauma 34, 32243237 (2017). 
10. Zeiler, F. A. et al. Pressure Autoregulation Measurement Techniques in Adult Traumatic Brain Injury, Part I: A Scoping Review of Intermittent/Semi-Intermittent Methods. J. Neurotrauma 34, 3207-3223 (2017).

11. Crawford, F. et al. Identification of plasma biomarkers of TBI outcome using proteomic approaches in an APOE mouse model. J. Neurotrauma 29, 246-260 (2012).

12. Jiang, L. et al. Effects of ApoE on intracellular calcium levels and apoptosis of neurons after mechanical injury. Neuroscience 301, 375-383 (2015).

13. McAllister, T. W. Neurobiological consequences of traumatic brain injury. Dialogues Clin. Neurosci. 13, 287-300 (2011).

14. Zeiler, F. A. et al. Genetic Influences on Patient Oriented Outcomes in TBI: A Living Systematic Review of Non-APOE Single Nucleotide Polymorphisms. J. Neurotrauma (2018). doi:10.1089/neu.2017.5583

15. Janowitz, T. \& Menon, D. K. Exploring new routes for neuroprotective drug development in traumatic brain injury. Sci. Transl. Med. 2, 27rv1 (2010).

16. Stovell, M. G. et al. Assessing Metabolism and Injury in Acute Human Traumatic Brain Injury with Magnetic Resonance Spectroscopy: Current and Future Applications. Front. Neurol. 8, 426 (2017).

17. Bomba, L., Walter, K. \& Soranzo, N. The impact of rare and low-frequency genetic variants in common disease. Genome Biol. 18, 77 (2017).

18. Lassen, N. A. Cerebral blood flow and oxygen consumption in man. Physiol. Rev. 39, 183238 (1959). 
19. Needham, E. et al. Cerebral Perfusion Pressure Targets Individualized to Pressure-Reactivity Index in Moderate to Severe Traumatic Brain Injury: A Systematic Review. J. Neurotrauma 34, 963-970 (2017).

20. Donnelly, J. et al. Pressure Reactivity-Based Optimal Cerebral Perfusion Pressure in a Traumatic Brain Injury Cohort. Acta Neurochir. Suppl. 126, 209-212 (2018).

21. Aries, M. J. H. et al. Continuous determination of optimal cerebral perfusion pressure in traumatic brain injury. Crit. Care Med. 40, 2456-2463 (2012).

22. Winn, H. Youmans Neurological Surgery. (Saunders, 2011).

23. Paulson, O. B., Strandgaard, S. \& Edvinsson, L. Cerebral autoregulation. Cerebrovasc. Brain Metab. Rev. 2, 161-192 (1990).

24. Jin Yang, null \& Clark, J. W. On the roles of vascular smooth muscle contraction in cerebral blood flow autoregulation - a modeling perspective. Conf. Proc. Annu. Int. Conf. IEEE Eng. Med. Biol. Soc. IEEE Eng. Med. Biol. Soc. Annu. Conf. 2015, 7796-7799 (2015).

25. Aaslid, R. Cerebral autoregulation and vasomotor reactivity. Front. Neurol. Neurosci. 21, 216-228 (2006).

26. Izzard, A. S. \& Heagerty, A. M. Myogenic properties of brain and cardiac vessels and their relation to disease. Curr. Vasc. Pharmacol. 12, 829-835 (2014).

27. Gebremedhin, D., Gopalakrishnan, S. \& Harder, D. R. Endogenous events modulating myogenic regulation of cerebrovascular function. Curr. Vasc. Pharmacol. 12, 810-817 (2014).

28. Koller, A. \& Toth, P. Contribution of flow-dependent vasomotor mechanisms to the autoregulation of cerebral blood flow. J. Vasc. Res. 49, 375-389 (2012). 
29. Faraci, F. M., Baumbach, G. L. \& Heistad, D. D. Myogenic mechanisms in the cerebral circulation. J. Hypertens. Suppl. Off. J. Int. Soc. Hypertens. 7, S61-64; discussion S65 (1989).

30. Terashvili, M., Pratt, P. F., Gebremedhin, D., Narayanan, J. \& Harder, D. R. Reactive oxygen species cerebral autoregulation in health and disease. Pediatr. Clin. North Am. 53, 1029-1037, xi (2006).

31. Ma, L. et al. Transcranial Doppler-based assessment of cerebral autoregulation in critically ill children during diabetic ketoacidosis treatment. Pediatr. Crit. Care Med. J. Soc. Crit. Care Med. World Fed. Pediatr. Intensive Crit. Care Soc. 15, 742-749 (2014).

32. Nakada, T. The Molecular Mechanisms of Neural Flow Coupling: A New Concept. J. Neuroimaging Off. J. Am. Soc. Neuroimaging 25, 861-865 (2015).

33. Murkin, J. M. Cerebral autoregulation: the role of $\mathrm{CO} 2$ in metabolic homeostasis. Semin. Cardiothorac. Vasc. Anesth. 11, 269-273 (2007).

34. Palmer, G. C. Neurochemical coupled actions of transmitters in the microvasculature of the brain. Neurosci. Biobehav. Rev. 10, 79-101 (1986).

35. Hall, C. N. et al. Capillary pericytes regulate cerebral blood flow in health and disease. Nature 508, 55-60 (2014).

36. Brian, J. E., Faraci, F. M. \& Heistad, D. D. Recent insights into the regulation of cerebral circulation. Clin. Exp. Pharmacol. Physiol. 23, 449-457 (1996).

37. Zeiler, F. A. et al. Cerebrospinal Fluid and Microdialysis Cytokines in Severe Traumatic Brain Injury: A Scoping Systematic Review. Front. Neurol. 8, 331 (2017).

38. Zeiler, F. A. et al. Cerebrospinal Fluid and Microdialysis Cytokines in Aneurysmal Subarachnoid Hemorrhage: A Scoping Systematic Review. Front. Neurol. 8, 379 (2017). 
39. Gao, L., Smielewski, P., Czosnyka, M. \& Ercole, A. Early Asymmetric Cardio-Cerebral Causality and Outcome after Severe Traumatic Brain Injury. J. Neurotrauma 34, 2743-2752 (2017).

40. Toth, P. et al. Traumatic brain injury-induced autoregulatory dysfunction and spreading depression-related neurovascular uncoupling: Pathomechanisms, perspectives, and therapeutic implications. Am. J. Physiol. Heart Circ. Physiol. 311, H1118-H1131 (2016).

41. Pramanik, K. et al. Dusp-5 and Snrk-1 coordinately function during vascular development and disease. Blood 113, 1184-1191 (2009).

42. Fan, F. et al. Zinc-finger nuclease knockout of dual-specificity protein phosphatase-5 enhances the myogenic response and autoregulation of cerebral blood flow in FHH.1BN rats. PloS One 9, e112878 (2014).

43. Islam, M. Advances in experimental medicine and biology: transient receptor potential channels. (Springer, 2011).

44. Zeiler, F. A. NMDA Receptor Antagonism in Refractory Status Epilepticus: Right Idea, Wrong Target? Brain Disord Ther 4, 195 (2015).

45. Ren, L. et al. Quantitative Analysis of Mouse Dural Afferent Neurons Expressing TRPM8, VGLUT3, and NF200. Headache 58, 88-101 (2018).

46. Kim, Y. S., Kim, T. H., McKemy, D. D. \& Bae, Y. C. Expression of vesicular glutamate transporters in transient receptor potential melastatin 8 (TRPM8)-positive dental afferents in the mouse. Neuroscience 303, 378-388 (2015).

47. Griessenauer, C. J. et al. Associations of renin-angiotensin system genetic polymorphisms and clinical course after aneurysmal subarachnoid hemorrhage. J. Neurosurg. 126, 15851597 (2017). 
48. Griessenauer, C. J. et al. Associations between endothelin polymorphisms and aneurysmal subarachnoid hemorrhage, clinical vasospasm, delayed cerebral ischemia, and functional outcome. J. Neurosurg. 1-7 (2017). doi:10.3171/2016.12.JNS162594

49. Hajjar, I. et al. Renin angiotensin system gene polymorphisms and cerebral blood flow regulation: the MOBILIZE Boston study. Stroke 41, 635-640 (2010).

50. Dardiotis, E. et al. Effect of angiotensin-converting enzyme tag single nucleotide polymorphisms on the outcome of patients with traumatic brain injury. Pharmacogenet. Genomics 25, 485-490 (2015).

51. Ariza, M. et al. Influence of Angiotensin-converting enzyme polymorphism on neuropsychological subacute performance in moderate and severe traumatic brain injury. $J$. Neuropsychiatry Clin. Neurosci. 18, 39-44 (2006).

52. Levinsson, A., Olin, A.-C., Björck, L., Rosengren, A. \& Nyberg, F. Nitric oxide synthase (NOS) single nucleotide polymorphisms are associated with coronary heart disease and hypertension in the INTERGENE study. Nitric Oxide Biol. Chem. 39, 1-7 (2014).

53. Lin, C.-L. et al. Attenuation of experimental subarachnoid hemorrhage--induced cerebral vasospasm by the adenosine A2A receptor agonist CGS 21680. J. Neurosurg. 106, 436-441 (2007).

54. Szpecht, D., Gadzinowski, J., Seremak-Mrozikiewicz, A., Kurzawińska, G. \& Szymankiewicz, M. Role of endothelial nitric oxide synthase and endothelin-1 polymorphism genes with the pathogenesis of intraventricular hemorrhage in preterm infants. Sci. Rep. 7, 42541 (2017).

55. Robertson, C. S. et al. Variants of the endothelial nitric oxide gene and cerebral blood flow after severe traumatic brain injury. J. Neurotrauma 28, 727-737 (2011). 
56. Rosalind Lai, P. M. \& Du, R. Role of Genetic Polymorphisms in Predicting Delayed Cerebral Ischemia and Radiographic Vasospasm After Aneurysmal Subarachnoid Hemorrhage: A Meta-Analysis. World Neurosurg. 84, 933-941.e2 (2015).

57. Hendrix, P. et al. Endothelial Nitric Oxide Synthase Polymorphism Is Associated with Delayed Cerebral Ischemia Following Aneurysmal Subarachnoid Hemorrhage. World Neurosurg. 101, 514-519 (2017).

58. Kondratieva, N. et al. Biomarkers of migraine: Part 1 - Genetic markers. J. Neurol. Sci. 369, 63-76 (2016).

59. Lin, C. L. et al. The effect of an adenosine A1 receptor agonist in the treatment of experimental subarachnoid hemorrhage-induced cerebrovasospasm. Acta Neurochir. (Wien) 148, 873-879; discussion 879 (2006).

60. Padmanabhan, S., Aman, A. \& Dominiczak, A. F. Genomics of hypertension. Pharmacol. Res. 121, 219-229 (2017).

61. Gupta, R. M. et al. A Genetic Variant Associated with Five Vascular Diseases Is a Distal Regulator of Endothelin-1 Gene Expression. Cell 170, 522-533.e15 (2017).

62. Machida, T., Iizuka, K. \& Hirafuji, M. 5-hydroxytryptamine and its receptors in systemic vascular walls. Biol. Pharm. Bull. 36, 1416-1419 (2013).

63. Gamoh, S., Hisa, H. \& Yamamoto, R. 5-hydroxytryptamine receptors as targets for drug therapies of vascular-related diseases. Biol. Pharm. Bull. 36, 1410-1415 (2013).

64. Winkler, E. A. et al. COMT Val 158 Met polymorphism is associated with nonverbal cognition following mild traumatic brain injury. Neurogenetics $\mathbf{1 7}, 31-41$ (2016). 
65. Winkler, E. A. et al. COMT Val158Met polymorphism is associated with post-traumatic stress disorder and functional outcome following mild traumatic brain injury. J. Clin. Neurosci. Off. J. Neurosurg. Soc. Australas. 35, 109-116 (2017).

66. Lipsky, R. H. et al. Association of COMT Val158Met genotype with executive functioning following traumatic brain injury. J. Neuropsychiatry Clin. Neurosci. 17, 465-471 (2005).

67. Binder, D. K. \& Scharfman, H. E. Brain-derived neurotrophic factor. Growth Factors Chur Switz. 22, 123-131 (2004).

68. Chen, S.-P. et al. Brain-derived neurotrophic factor gene Val66Met polymorphism modulates reversible cerebral vasoconstriction syndromes. PloS One 6, e18024 (2011).

69. Kasselman, L. J. et al. BDNF: a missing link between sympathetic dysfunction and inflammatory disease? J. Neuroimmunol. 175, 118-127 (2006).

70. Failla, M. D. et al. Variation in the BDNF gene interacts with age to predict mortality in a prospective, longitudinal cohort with severe TBI. Neurorehabil. Neural Repair 29, 234-246 (2015).

71. Bagnato, S. et al. Brain-derived neurotrophic factor (Val66Met) polymorphism does not influence recovery from a post-traumatic vegetative state: a blinded retrospective multicentric study. J. Neurotrauma 29, 2050-2059 (2012).

72. Krueger, F. et al. The role of the Met66 brain-derived neurotrophic factor allele in the recovery of executive functioning after combat-related traumatic brain injury. J. Neurosci. Off. J. Soc. Neurosci. 31, 598-606 (2011).

73. McAllister, T. W. et al. Polymorphisms in the brain-derived neurotrophic factor gene influence memory and processing speed one month after brain injury. J. Neurotrauma 29, $1111-1118$ (2012). 
74. Jing, D., Lee, F. S. \& Ninan, I. The BDNF Val66Met polymorphism enhances glutamatergic transmission but diminishes activity-dependent synaptic plasticity in the dorsolateral striatum. Neuropharmacology 112, 84-93 (2017).

75. Lemos, C. et al. BDNF and CGRP interaction: implications in migraine susceptibility. Cephalalgia Int. J. Headache 30, 1375-1382 (2010).

76. Failla, M. D. et al. Variants of SLC6A4 in depression risk following severe TBI. Brain Inj. 27, 696-706 (2013).

77. Pardini, M. et al. Prefrontal cortex lesions and MAO-A modulate aggression in penetrating traumatic brain injury. Neurology 76, 1038-1045 (2011).

78. Bano, D. \& Ankarcrona, M. Beyond the critical point: An overview of excitotoxicity, calcium overload and the downstream consequences. Neurosci. Lett. 663, 79-85 (2018).

79. Sutherland, H. G. \& Griffiths, L. R. Genetics of Migraine: Insights into the Molecular Basis of Migraine Disorders. Headache 57, 537-569 (2017).

80. Timofeev, I. et al. Interaction between brain chemistry and physiology after traumatic brain injury: impact of autoregulation and microdialysis catheter location. J. Neurotrauma $\mathbf{2 8 ,}$ 849-860 (2011).

81. Zeiler, F. A. et al. A systematic review of cerebral microdialysis and outcomes in TBI: relationships to patient functional outcome, neurophysiologic measures, and tissue outcome. Acta Neurochir. (Wien) 159, 2245-2273 (2017).

82. Kanai, Y. et al. The SLC1 high-affinity glutamate and neutral amino acid transporter family. Mol. Aspects Med. 34, 108-120 (2013).

83. Madura, S. A. et al. Genetic variation in SLC17A7 promoter associated with response to sport-related concussions. Brain Inj. 30, 908-913 (2016). 
84. McDevitt, J. et al. Association between GRIN2A promoter polymorphism and recovery from concussion. Brain Inj. 29, 1674-1681 (2015).

85. Stam, A. H. et al. Early seizures and cerebral oedema after trivial head trauma associated with the CACNA1A S218L mutation. J. Neurol. Neurosurg. Psychiatry 80, 1125-1129 (2009).

86. Barron, J. T. \& Nair, A. Lactate depresses sarcolemmal permeability of $\mathrm{Ca} 2+$ in intact arterial smooth muscle. Life Sci. 74, 651-662 (2003).

87. Doll, D. N. et al. Mitochondrial crisis in cerebrovascular endothelial cells opens the bloodbrain barrier. Stroke 46, 1681-1689 (2015).

88. Brady, K. M. et al. Continuous measurement of autoregulation by spontaneous fluctuations in cerebral perfusion pressure: comparison of 3 methods. Stroke 39, 2531-2537 (2008).

89. Bulstrode, H. et al. Mitochondrial DNA and traumatic brain injury. Ann. Neurol. 75, 186195 (2014).

90. Conley, Y. P. et al. Mitochondrial polymorphisms impact outcomes after severe traumatic brain injury. J. Neurotrauma 31, 34-41 (2014).

91. Cousar, J. L. et al. Influence of ATP-binding cassette polymorphisms on neurological outcome after traumatic brain injury. Neurocrit. Care 19, 192-198 (2013).

92. Jha, R. M. et al. ABCC8 Single Nucleotide Polymorphisms are Associated with Cerebral Edema in Severe TBI. Neurocrit. Care 26, 213-224 (2017).

93. Dardiotis, E. et al. AQP4 tag single nucleotide polymorphisms in patients with traumatic brain injury. J. Neurotrauma 31, 1920-1926 (2014). 
94. Roberts, D. J. et al. Association between the cerebral inflammatory and matrix metalloproteinase responses after severe traumatic brain injury in humans. J. Neurotrauma 30, 1727-1736 (2013).

95. Guilfoyle, M. R. et al. Matrix Metalloproteinase Expression in Contusional Traumatic Brain Injury: A Paired Microdialysis Study. J. Neurotrauma 32, 1553-1559 (2015).

96. Rochfort, K. D. \& Cummins, P. M. Thrombomodulin regulation in human brain microvascular endothelial cells in vitro: role of cytokines and shear stress. Microvasc. Res. 97, 1-5 (2015).

97. Dardiotis, E., Dardioti, M., Hadjigeorgiou, G. M. \& Paterakis, K. Re: Lack of association between the IL1A gene (-889) polymorphism and outcome after head injury. Tanriverdi T et al. Surg Neurol 2006;65:7-10; discussion 10. Surg. Neurol. 66, 334-335 (2006).

98. Miñambres, E. et al. Correlation between transcranial interleukin-6 gradient and outcome in patients with acute brain injury. Crit. Care Med. 31, 933-938 (2003).

99. Uzan, M. et al. Association between interleukin-1 beta (IL-1beta) gene polymorphism and outcome after head injury: an early report. Acta Neurochir. (Wien) 147, 715-720; discussion $720(2005)$.

100. Waters, R. J. et al. Cytokine gene polymorphisms and outcome after traumatic brain injury. J. Neurotrauma 30, 1710-1716 (2013).

101. Sinha, S., Monsoori, N., Mukhopadhyay, A. \& Sharma, B. Effect of IL-6-174 G/C polymorphism in predicting disability and functional outcome in patients with severe traumatic brain injury (STBI). J. Neurotrauma 112, 673 (2015).

102. Lavinio, A. et al. Cerebrovascular reactivity and autonomic drive following traumatic brain injury. Acta Neurochir. Suppl. 102, 3-7 (2008). 
103. Perkes, I., Baguley, I. J., Nott, M. T. \& Menon, D. K. A review of paroxysmal sympathetic hyperactivity after acquired brain injury. Ann. Neurol. 68, 126-135 (2010).

104. Meyfroidt, G., Baguley, I. J. \& Menon, D. K. Paroxysmal sympathetic hyperactivity: the storm after acute brain injury. Lancet Neurol. 16, 721-729 (2017).

105. Sykora, M. et al. Autonomic Impairment in Severe Traumatic Brain Injury: A Multimodal Neuromonitoring Study. Crit. Care Med. 44, 1173-1181 (2016).

106. Ayata, C. \& Lauritzen, M. Spreading Depression, Spreading Depolarizations, and the Cerebral Vasculature. Physiol. Rev. 95, 953-993 (2015).

107. Burrello, J. et al. Is There a Role for Genomics in the Management of Hypertension? Int. J. Mol. Sci. 18, (2017).

108. Heusch, G., Erbel, R. \& Siffert, W. Genetic determinants of coronary vasomotor tone in humans. Am. J. Physiol. Heart Circ. Physiol. 281, H1465-1468 (2001).

109. Andreassi, M. G. et al. Adenosine A2(A) receptor gene polymorphism (1976C>T) affects coronary flow reserve response during vasodilator stress testing in patients with non ischemic-dilated cardiomyopathy. Pharmacogenet. Genomics 21, 469-475 (2011).

110. Sato, M. et al. Association between prostaglandin E2 receptor gene and essential hypertension. Prostaglandins Leukot. Essent. Fatty Acids 77, 15-20 (2007).

111. Coughlin, S. S. Toward a road map for global -omics: a primer on -omic technologies. Am. J. Epidemiol. 180, 1188-1195 (2014).

112. Verghese, A. et al. Factors associated with the course and outcome of schizophrenia. Indian J. Psychiatry 27, 201-206 (1985).

113. Evans, D. M. \& Purcell, S. Power calculations in genetic studies. Cold Spring Harb. Protoc. 2012, 664-674 (2012). 
114. Nsengimana, J. \& Bishop, D. T. Design considerations for genetic linkage and association studies. Methods Mol. Biol. Clifton NJ 850, 237-262 (2012).

115. Darby, J. M., Yonas, H., Marion, D. W. \& Latchaw, R. E. Local 'inverse steal' induced by hyperventilation in head injury. Neurosurgery 23, 84-88 (1988).

116. Zeiler, F. A. et al. Intra- and Extra-Cranial Injury Burden as Drivers of Impaired Cerebrovascular Reactivity in Traumatic Brain Injury. J. Neurotrauma (2018). doi:10.1089/neu.2017.5595

117. Hiler, M. et al. Predictive value of initial computerized tomography scan, intracranial pressure, and state of autoregulation in patients with traumatic brain injury. J. Neurosurg. 104, 731-737 (2006).

118. Schmidt, E. A. et al. Symmetry of cerebral hemodynamic indices derived from bilateral transcranial Doppler. J. Neuroimaging Off. J. Am. Soc. Neuroimaging 13, 248-254 (2003).

119. Schmidt, E. A. et al. Asymmetry of pressure autoregulation after traumatic brain injury. J. Neurosurg. 99, 991-998 (2003).

120. Armstead, W. M. Cerebral Blood Flow Autoregulation and Dysautoregulation. Anesthesiol. Clin. 34, 465-477 (2016).

121. Armstead, W. M., Riley, J. \& Vavilala, M. S. Preferential Protection of Cerebral Autoregulation and Reduction of Hippocampal Necrosis With Norepinephrine After Traumatic Brain Injury in Female Piglets. Pediatr. Crit. Care Med. J. Soc. Crit. Care Med. World Fed. Pediatr. Intensive Crit. Care Soc. 17, e130-137 (2016).

122. Burkhart, C. S. et al. Effect of age on intraoperative cerebrovascular autoregulation and near-infrared spectroscopy-derived cerebral oxygenation. Br. J. Anaesth. 107, 742-748 (2011). 
123. Czosnyka, M., Czosnyka, Z. H., Whitfield, P. C., Donovan, T. \& Pickard, J. D. Age dependence of cerebrospinal pressure-volume compensation in patients with hydrocephalus. J. Neurosurg. 94, 482-486 (2001).

124. Czosnyka, M. et al. Age, intracranial pressure, autoregulation, and outcome after brain trauma. J. Neurosurg. 102, 450-454 (2005).

125. Mutch, W. A. C. et al. Patient-Specific Alterations in CO2 Cerebrovascular Responsiveness in Acute and Sub-Acute Sports-Related Concussion. Front. Neurol. 9, 23 (2018).

126. Ellis, M. J. et al. Neuroimaging Assessment of Cerebrovascular Reactivity in Concussion: Current Concepts, Methodological Considerations, and Review of the Literature. Front. Neurol. 7, 61 (2016).

127. Barlow, K. M. et al. Cerebral Perfusion Changes in Post-Concussion Syndrome: A Prospective Controlled Cohort Study. J. Neurotrauma 34, 996-1004 (2017).

128. Yue, J. K. et al. Transforming research and clinical knowledge in traumatic brain injury pilot: multicenter implementation of the common data elements for traumatic brain injury. $J$. Neurotrauma 30, 1831-1844 (2013).

129. Maas, A. I. R. et al. Collaborative European NeuroTrauma Effectiveness Research in Traumatic Brain Injury (CENTER-TBI): a prospective longitudinal observational study. Neurosurgery 76, 67-80 (2015).

130. Czosnyka, M., Miller, C. \& Participants in the International Multidisciplinary Consensus Conference on Multimodality Monitoring. Monitoring of cerebral autoregulation. Neurocrit. Care 21 Suppl 2, S95-102 (2014). 
131. Zeiler, F. A., Lee, J. K., Smielewski, P., Czosnyka, M. \& Brady, K. Validation of ICP derived cerebrovascular reactivity indices against the lower limit of autoregulation, Part II: experimental model of arterial hypotension. J Neurotrauma Epub Ahead of Print, (2018).

132. Zeiler, F. A. et al. Validation of pressure reactivity and pulse amplitude indices against the lower limit of autoregulation, Part I: experimental intra-cranial hypertension. $J$ Neurotrauma In Press, (2018).

133. Zeiler, F. A. \& Smielewski, P. Application of robotic transcranial Doppler for extended duration recording in moderate/severe traumatic brain injury: first experiences. Crit.

Ultrasound J. 10, 16 (2018).

134. Zeiler, F. A. et al. Continuous Autoregulatory Indices Derived from Multi-Modal Monitoring: Each One Is Not Like the Other. J. Neurotrauma 34, 3070-3080 (2017).

135. Zeiler, F. A. et al. Estimating Pressure Reactivity Index Using Non-Invasive Doppler Based Systolic Flow Index. J. Neurotrauma (2018). doi:10.1089/neu.2017.5596

136. Hutchinson, P. J. et al. Consensus statement from the 2014 International Microdialysis Forum. Intensive Care Med. 41, 1517-1528 (2015).

137. Hutchinson, P., O’Phelan, K. \& Participants in the International Multidisciplinary Consensus Conference on Multimodality Monitoring. International multidisciplinary consensus conference on multimodality monitoring: cerebral metabolism. Neurocrit. Care $\mathbf{2 1}$ Suppl 2, S148-158 (2014).

138. Newcombe, P. J., Conti, D. V. \& Richardson, S. JAM: A Scalable Bayesian Framework for Joint Analysis of Marginal SNP Effects. Genet. Epidemiol. 40, 188-201 (2016).

139. Visscher, P. M. et al. 10 Years of GWAS Discovery: Biology, Function, and Translation. Am. J. Hum. Genet. 101, 5-22 (2017). 
140. Bergmeijer, T. O. et al. Genome-wide and candidate gene approaches of clopidogrel efficacy using pharmacodynamic and clinical end points-Rationale and design of the International Clopidogrel Pharmacogenomics Consortium (ICPC). Am. Heart J. 198, 152159 (2018).

141. Long, T. et al. Whole-genome sequencing identifies common-to-rare variants associated with human blood metabolites. Nat. Genet. 49, 568-578 (2017).

142. Budohoski, K. P. et al. Monitoring cerebral autoregulation after head injury. Which component of transcranial Doppler flow velocity is optimal? Neurocrit. Care 17, 211-218 (2012).

143. Zweifel, C. et al. Continuous assessment of cerebral autoregulation with near-infrared spectroscopy in adults after subarachnoid hemorrhage. Stroke 41, 1963-1968 (2010). 
Figure 1 I Potential role of genetic polymorphisms in the control of cerebral autoregulation

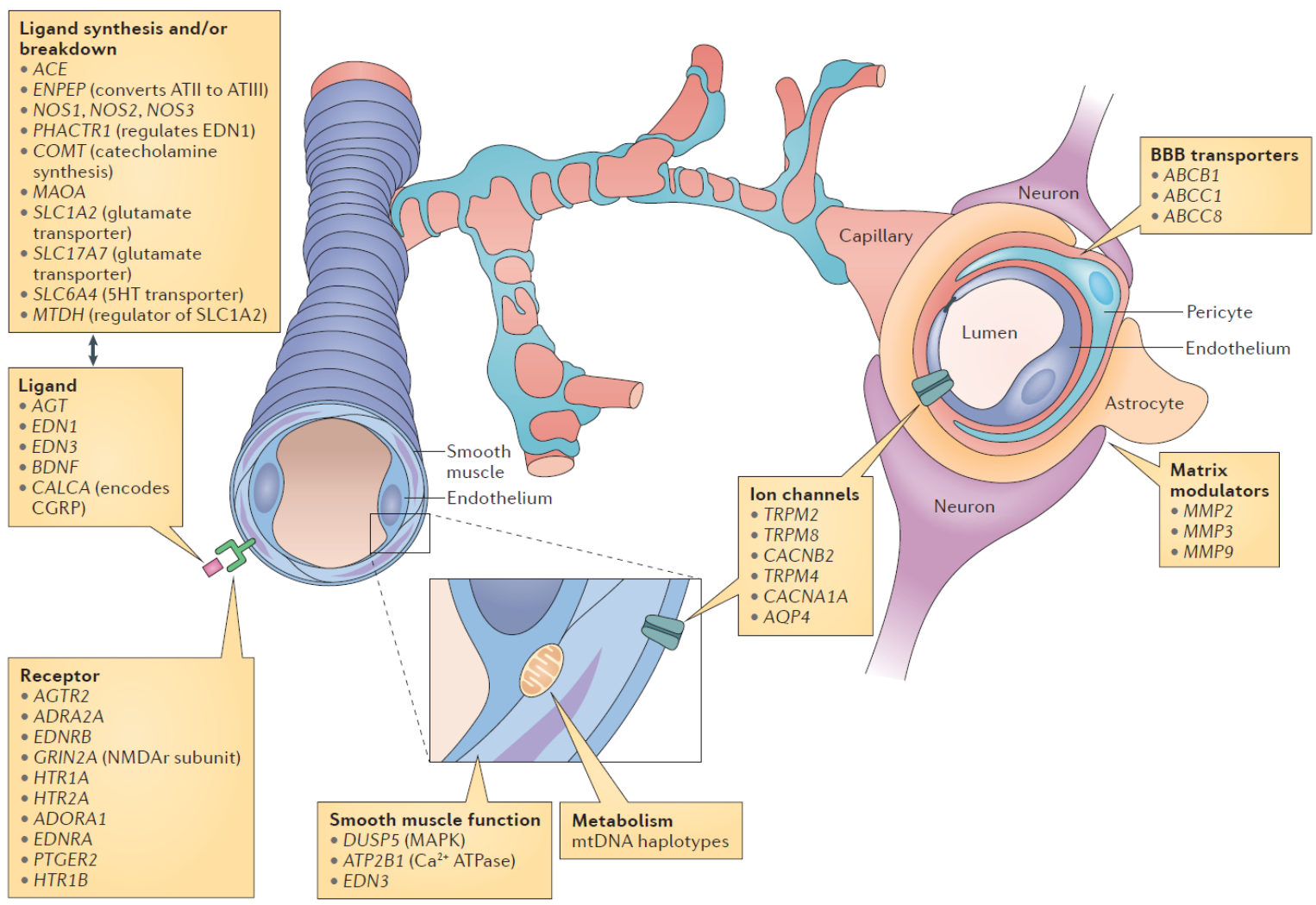

Summary of the theorized mechanisms and genetic polymorphisms involved in the modulation of cerebrovascular tone. Figure displays a cerebral arteriole, with smooth muscle and endothelial layers, with surrounding pericyte and astrocyte. Left side of figure highlights genetic polymorphisms that are potentially involved in neurotransmitter or endothelial responses to changes in perfusion pressure, with genes subcategorized into ligand synthesis and/or breakdown, ligands, and receptors. The bottom portion highlights genes involved in smooth muscle function, ion channels and metabolism. Finally, the right side of the figure lists genes potentially involved in blood-brain-barrier integrity and matrix modulation. 
Table 1 |Candidate polymorphisms linked to the cerebrovascular myogenic response

\begin{tabular}{|c|c|c|c|c|}
\hline$\frac{\text { Gene }}{\text { name }}$ & $\begin{array}{l}\text { Variant- } \\
\text { associated } \\
\text { Polymorphism } \\
\text { :rs number or } \\
\text { mutation } \\
\end{array}$ & $\frac{\text { Chromo }}{\text { some }}$ & Protein and role & $\begin{array}{l}\text { Relevant pathological } \\
\text { conditions associated to } \\
\text { date with polymorphisms }\end{array}$ \\
\hline DUSP5 $5^{41,42}$ & $\begin{array}{l}\text { A wide variety } \\
\text { of SNPs } \\
\text { identified to } \\
\text { date }\end{array}$ & $10 q 25.2$ & $\begin{array}{l}\text { Dusp5. A serine-threonine } \\
\text { phosphatase that inactivates } \\
\text { MAPK, resulting in decreased } \\
\text { regulation of calcium activated } \\
\text { potassium channels and TRP } \\
\text { channels. }\end{array}$ & $\begin{array}{l}\text { None described in humans } \\
\text { to date, but potential for a } \\
\text { variety of vascular issues } \\
\text { exists. }\end{array}$ \\
\hline TRPM2 $2^{43,44}$ & $\begin{array}{l}\text { A wide variety } \\
\text { SNPs } \\
\text { identified to } \\
\text { date that are } \\
\text { linked to } \\
\text { dysfunction } \\
\end{array}$ & $21 q 22.3$ & $\begin{array}{l}\text { TRPM2. A calcium permeable } \\
\text { cation channel that has a } \\
\text { potential role in vascular tone } \\
\text { and excitotoxicity. }\end{array}$ & $\begin{array}{l}\text {-Potential role in status } \\
\text { epilepticus and glutamate- } \\
\text { mediated excitotoxicity. } \\
\text {-Potential downstream } \\
\text { mediator of vascular tone. }\end{array}$ \\
\hline TRPM $^{43}$ & $\begin{array}{l}\text { A wide variety } \\
\text { SNPs } \\
\text { identified to } \\
\text { date that are } \\
\text { linked to } \\
\text { cardiovascular } \\
\text { dysfunction. }\end{array}$ & $19 q 33.3$ & $\begin{array}{l}\text { TRPM4. A calcium permeable } \\
\text { cation channel that has a } \\
\text { potential role in vascular tone } \\
\text { and excitotoxicity. }\end{array}$ & $\begin{array}{l}\text {-Cardiovascular dysfunction } \\
\text {-Glutamate-mediated } \\
\text { excitotoxicity } \\
\text {-Potential downstream } \\
\text { mediator of vascular tone }\end{array}$ \\
\hline $\begin{array}{l}\text { TRPM8 }{ }^{43,45,} \\
46\end{array}$ & $\begin{array}{l}\text { rs17862920 } \\
\text { rs10166942 } \\
\text { rs17863838 } \\
\text { rs10187654 } \\
\text { rs10166942 }\end{array}$ & $2 q 37.1$ & $\begin{array}{l}\text { TRPM8. A calcium permeable } \\
\text { cation channel, known to be } \\
\text { involved in calcium regulation, } \\
\text { and has a potential role in } \\
\text { vascular tone. Mutations can } \\
\text { lead to both loss of function } \\
\text { and increased calcium } \\
\text { transport, and mediate a } \\
\text { variety of downstream effects. }\end{array}$ & -Migraine \\
\hline $\mathrm{ACE}^{47,48}$ & $\begin{array}{l}\text { rs4340 (aka. } \\
\text { rs464994) } \\
\text { rs1799752 } \\
\text { rs7221780 } \\
\text { rs8066276 }\end{array}$ & $17 q 23.3$ & $\begin{array}{l}\text { Angiotensin converting } \\
\text { enzyme. Cleaves } \\
\text { angiotensinogen to } \\
\text { angiotensin I. Mutation leads } \\
\text { increased circulating levels of } \\
\text { angiotensin I. }\end{array}$ & $\begin{array}{l}\text {-SAH related VSP (rs4340) } \\
\text {-haemorrhagic stroke } \\
\text { (rs1799752) } \\
\text {-Poor global outcome post- } \\
\text { TBI (rs7221780, rs8066276) } \\
\text {-Poor neuropsychiatric } \\
\text { performance post-TBI } \\
\text { (rs4340) }\end{array}$ \\
\hline $\mathrm{AT}^{47}$ & rs11091046 & $\mathrm{Xq23}$ & $\begin{array}{l}\text { Angiotensin type } 2 \text { receptor. } \\
\text { The major agonist of this }\end{array}$ & $\begin{array}{l}\text {-Essential hypertension } \\
\text {-SAH related VSP }\end{array}$ \\
\hline
\end{tabular}




\begin{tabular}{|c|c|c|c|c|}
\hline & & & $\begin{array}{l}\text { receptor is angiotensin II. } \\
\text { Mutation leads to enhanced } \\
\text { binding of angiotensin II, } \\
\text { resulting in gain-of-function } \\
\text { effects that mediate increased } \\
\text { vasopressor effects and } \\
\text { subsequent vascular } \\
\text { remodeling in association with } \\
\text { the RAS. }\end{array}$ & \\
\hline $\mathrm{AGT}^{49}$ & $\begin{array}{l}\text { rs699 } \\
\text { rs2004776 }\end{array}$ & $1 q 42.2$ & $\begin{array}{l}\text { Angiotensinogen. Mutation } \\
\text { potentially leads to increased } \\
\text { angiotensin I levels and } \\
\text { increased hemodynamic } \\
\text { effects. Linked to } \\
\text { autoregulation dysfunction. }\end{array}$ & $\begin{array}{l}\text {-Essential hypertension } \\
\text { (rs699, rs2004776) } \\
\text {-Impaired autoregulation in } \\
\text { healthy volunteers (rs699) }\end{array}$ \\
\hline ENPEP 60 & $\begin{array}{l}\text { rs33966350 } \\
\text { rs6825911 }\end{array}$ & $4 q 25$ & $\begin{array}{l}\text { Glutamyl aminopeptidase. } \\
\text { Converts angiotensin II to } \\
\text { angiotensin III. Mutations lead } \\
\text { to reduced function and } \\
\text { protein byproducts which } \\
\text { stimulate angiotensin type } 1 \\
\text { receptors. }\end{array}$ & -Essential hypertension \\
\hline ATP2B160 & rs17249754 & $\begin{array}{l}12 q 21.3 \\
3\end{array}$ & $\begin{array}{l}\text { Calcium ATPase. Plays a major } \\
\text { part in intracellular calcium } \\
\text { homeostasis. Mutation leads } \\
\text { to increased vascular tone. }\end{array}$ & -Essential hypertension \\
\hline
\end{tabular}

$\mathrm{ACE}=$ angiotensin converting enzyme, $\mathrm{AGT}$ = angiotensinogen, $\mathrm{AT}=$ angiotensin type, DUSP = dual specificity phosphatase, $\mathrm{MAPK}=$ mitogen activated protein kinase, $r s=$ reference number for SNP,

$\mathrm{SAH}=$ subarachnoid haemorrhage, SNP = single nucleotide polymorphism, TBI = traumatic brain injury, TRPM = transient receptor protein type-M, VSP = vasospasm. All SNP information was gained from the referenced literature and through both ClinVar and dbSNP online databases 
Table 2 Candidate polymorphisms linked to endothelial mediation of cerebral autoregulation.

\begin{tabular}{|c|c|c|c|c|}
\hline Gene name & $\begin{array}{l}\frac{\text { Variant- }}{\text { associated }} \\
\text { Polymorphism: rs } \\
\frac{\text { number or }}{\text { mutation }}\end{array}$ & Chromosome & Protein and role & $\begin{array}{l}\text { Relevant } \\
\text { pathological } \\
\text { conditions } \\
\text { associated to date } \\
\begin{array}{l}\text { with } \\
\text { polymorphisms }\end{array}\end{array}$ \\
\hline ADORA $1^{53,59}$ & $\begin{array}{l}\text { rs3766553 } \\
\text { rs10920573 }\end{array}$ & $1 q 32.1$ & $\begin{array}{l}\text { Adenosine A1 receptor. } \\
\text { Mutations lead to failure } \\
\text { to induce the NOS } \\
\text { pathway and thus trend } \\
\text { toward vascular } \\
\text { constriction. }\end{array}$ & $\begin{array}{l}\text {-Linked to the } \\
\text { development of } \\
\text { early and late post- } \\
\text { traumatic epilepsy } \\
\text {-Linked to } \\
\text { vasospasm in animal } \\
\text { models of SAH. }\end{array}$ \\
\hline ADORA2A ${ }^{53,59}$ & $\begin{array}{l}\text { rs2298383 (1976 } \\
\text { C/T mutation) }\end{array}$ & $22 q 11.23$ & $\begin{array}{l}\text { Adenosine A2A receptor. } \\
\text { Mutation leads to failure } \\
\text { to induce the NOS } \\
\text { pathway, trending } \\
\text { towards impaired } \\
\text { modulation of vascular } \\
\text { tone. }\end{array}$ & $\begin{array}{l}\text {-Linked to } \\
\text { impairment of } \\
\text { dipyridamole- } \\
\text { mediated } \\
\text { vasodilation during } \\
\text { coronary stress } \\
\text { testing } \\
\text {-Linked to } \\
\text { vasospasm in animal } \\
\text { models of SAH }\end{array}$ \\
\hline EDN1 $^{54,58,60,61}$ & $\begin{array}{l}\text { rs2070699 } \\
\text { rs1626492 } \\
\text { rs1800541 }\end{array}$ & $6 \mathrm{p} 24.1$ & $\begin{array}{l}\text { Endothelin 1. A potent } \\
\text { vasoactive mediator. } \\
\text { Mutation leads to } \\
\text { altered vascular tone. }\end{array}$ & $\begin{array}{l}\text {-Migraine } \\
\text {-Increased risk of } \\
\text { aneurysmal SAH }\end{array}$ \\
\hline EDNRA $^{57,58}$ & $\begin{array}{l}(-231) A / G \\
\text { mutation } \\
\text { rs5335 }\end{array}$ & $\begin{array}{l}4 q 31.22- \\
\text { q31.23 }\end{array}$ & $\begin{array}{l}\text { Endothelin receptor type } \\
\text { A. Triggers } \\
\text { vasoconstriction. } \\
\text { Mutation leads to } \\
\text { altered function and can } \\
\text { increase vascular tone. }\end{array}$ & $\begin{array}{l}\text {-Migraine } \\
\text {-SAH related VSP }\end{array}$ \\
\hline EDNRB $^{58}$ & rs9544636 & $13 q 22.3$ & $\begin{array}{l}\text { Endothelin receptor type } \\
\text { B. A regulator of } \\
\text { vascular tone. Mutation } \\
\text { leads to altered tone } \\
\text { and subsequent altered } \\
\text { vascular tone. }\end{array}$ & -Migraine \\
\hline EDN3 $^{60}$ & rs6015450 & $20 q 13.32$ & $\begin{array}{l}\text { Mediator of endothelin } \\
3 \text { pathway. Mutation } \\
\text { leads to increase } \\
\text { vascular tone. }\end{array}$ & $\begin{array}{l}\text {-Essential } \\
\text { hypertension }\end{array}$ \\
\hline
\end{tabular}




\begin{tabular}{|c|c|c|c|c|}
\hline $\operatorname{NOS}^{52}$ & $\begin{array}{l}\text { rs41279104 } \\
\text { rs1060499530 }\end{array}$ & $12 q 24.22$ & $\begin{array}{l}\text { Neuronal nitric oxide } \\
\text { synthase. }\end{array}$ & -Cardiac defects \\
\hline $\operatorname{NOS} 2^{58}$ & $\begin{array}{l}\text { rs3833912 } \\
\text { rs2297518 } \\
\text { rs2779249 } \\
\text { rs2297518 }\end{array}$ & $17 q 11.2$ & $\begin{array}{l}\text { Inducible nitric oxide } \\
\text { synthase. Mutations } \\
\text { typically cause a loss of } \\
\text { function, leading to } \\
\text { vascular spasm. }\end{array}$ & -Migraine \\
\hline $\mathrm{NOS}^{52-57}$ & $\begin{array}{l}\text { rs2070744 (786 } \\
\text { C/T mutation) } \\
\text { rs1799983 (894 } \\
\text { G/A mutation) } \\
\text { rs3918226 } \\
\text { rs743506 } \\
\text { rs3918166 }\end{array}$ & $7 q 36.1$ & $\begin{array}{l}\text { Endothelial nitric oxide } \\
\text { synthase. Mutations } \\
\text { lead to loss of function } \\
\text { and increased risk of } \\
\text { vascular spasm. }\end{array}$ & $\begin{array}{l}\text {-Essential } \\
\text { hypertension } \\
\text {-Poor global } \\
\text { outcome in TBI } \\
\text {-Impaired } \\
\text { autoregulation in TBI } \\
\text {-Impaired } \mathrm{CO}_{2} \\
\text { reactivity in TBI } \\
\text {-Increased SAH } \\
\text { related VSP } \\
\text {-Linked to coronary } \\
\text { VSP } \\
\text {-Migraine }\end{array}$ \\
\hline PHACTR $^{61}$ & rs9349379 & $6 q 24.1$ & $\begin{array}{l}\text { Phosphatase and actin } \\
\text { regulator } 1 . \text { A regulator } \\
\text { of EDN1 activity, and } \\
\text { consequently of vascular } \\
\text { tone. }\end{array}$ & $\begin{array}{l}\text {-Essential } \\
\text { hypertension } \\
\text {-Coronary artery } \\
\text { disease } \\
\text {-Migraine }\end{array}$ \\
\hline PTGER2 ${ }^{62,63,110}$ & rs17197 & $14 q 22.1$ & $\begin{array}{l}\text { Prostaglandin E2 EP2 } \\
\text { receptor. }\end{array}$ & $\begin{array}{l}\text {-Essential } \\
\text { hypertension }\end{array}$ \\
\hline
\end{tabular}

EDN = endothelin, EDNR = endothelin receptor, NOS = nitric oxide synthase, $\mathrm{PHACTR}=$ phosphatase and actin regulatory protein, PTGER = prostaglandin $\mathrm{E}$ receptor, $\mathrm{rs}=$ reference number for SNP, SAH = subarachnoid hemorrhage, SNP = single nucleotide polymorphism, TBI = traumatic brain injury, VSP = vasospasm. All SNP information was gained from the referenced literature and through ClinVar and dbSNP online databases. 
Table 3 Candidate single nucleotide polymorphisms linked to neurotransmitter-based effects on cerebral autoregulation.

\begin{tabular}{|c|c|c|c|c|}
\hline Gene name & $\begin{array}{l}\frac{\text { Variant- }}{\text { associated }} \\
\frac{\text { Polymorphism: }}{\text { rs number or }} \\
\text { mutation }\end{array}$ & Chromosome & Protein and role & $\begin{array}{l}\text { Relevant } \\
\text { pathological } \\
\text { conditions } \\
\text { associated to date } \\
\text { with } \\
\text { Polymorphisms }\end{array}$ \\
\hline $\begin{array}{l}\text { BDNF }^{14,67-} \\
69,75\end{array}$ & $\begin{array}{l}\text { rs6265 } \\
\text { rs7124442 } \\
\text { rs2049046 }\end{array}$ & 11p14.1 & $\begin{array}{l}\text { Brain derived neurotropic } \\
\text { factor. A multi-function } \\
\text { protein. BDNF signaling has } \\
\text { downstream consequences } \\
\text { on cerebrovascular tone and } \\
\text { neuroinflammatory } \\
\text { response. } \\
\text { Mutation can lead to various } \\
\text { responses; for example, } \\
\text { poor localization to } \\
\text { secretory granules. }\end{array}$ & $\begin{array}{l}\text {-Migraine } \\
\text {-RCVS } \\
\text {-Global outcome in } \\
\text { TBI } \\
\text {-Neuropsychiatric } \\
\text { outcome in TBI }\end{array}$ \\
\hline CACNA1A $^{85}$ & S218L Mutation & $19 p 13$ & $\begin{array}{l}\text { Alpha-1 subunit of P/Q-type } \\
\text { calcium channels. These } \\
\text { channels mediate } \\
\text { neurotransmitter release. } \\
\text { The } \mathrm{S} 218 \mathrm{~L} \text { mutation } \\
\text { potentially leads to } \\
\text { increased neuronal influx of } \\
\text { calcium and enhanced } \\
\text { glutamate-mediated } \\
\text { excitotoxicity }\end{array}$ & $\begin{array}{l}\text {-Cerebral oedema } \\
\text { post-TBI } \\
\text {-Migraine } \\
\text {-SCD }\end{array}$ \\
\hline $\mathrm{CACNB2}^{58}$ & rs706100 & $10 \mathrm{p} 12$ & $\begin{array}{l}\text { Beta-2 subunit of P/Q-type } \\
\text { calcium channels. Involved } \\
\text { in neuronal calcium } \\
\text { homeostasis. The rs } 706100 \\
\text { mutation is believed to } \\
\text { trigger calcium influx and } \\
\text { glutamate-mediated } \\
\text { excitotoxicity }\end{array}$ & -Migraine \\
\hline CALCA $^{58,75}$ & rs1553005 & $11 p 15.2$ & $\begin{array}{l}\text { Calcitonin and calcitonin- } \\
\text { gene related peptides. } \\
\text { CALCA rs1553005 leads to }\end{array}$ & -Migraine \\
\hline
\end{tabular}




\begin{tabular}{|c|c|c|c|c|}
\hline & & & $\begin{array}{l}\text { migraine in conjunction with } \\
\text { BDNF rs2049046 SNP }\end{array}$ & \\
\hline $\mathrm{COMT}^{14,58}$ & rs4680 & $22 q 11.21$ & $\begin{array}{l}\text { Catechol-O- } \\
\text { methyltransferase. An } \\
\text { enzyme involved in the } \\
\text { metabolism of } \\
\text { catecholamine-based } \\
\text { neurotransmitters and } \\
\text { drugs. }\end{array}$ & $\begin{array}{l}\text {-Migraine } \\
\text {-Global outcome in } \\
\text { TBI is potentially } \\
\text { improved in Met } \\
\text { allele carriers } \\
\text {-Neuropsychiatric } \\
\text { outcome in TBI }\end{array}$ \\
\hline GRIN2A ${ }^{84}$ & $\begin{array}{l}\text { rs3219790 (VNTR } \\
\text { of GT tract) }\end{array}$ & $16 p 13.2$ & $\begin{array}{l}\text { NMDA receptor subunit. } \\
\text { Glutamate is the main } \\
\text { agonist of these channels. }\end{array}$ & $\begin{array}{l}\text {-Linked to } \\
\text { increased duration } \\
\text { of recovery in mild } \\
\text { TBI. }\end{array}$ \\
\hline HTR1A $^{58,62,63}$ & rs6295 & $5 q 12.3$ & $\begin{array}{l}\text { Serotonin receptor } 1 \mathrm{~A} \text {. } \\
\text { Serotonin is known to have } \\
\text { direct endothelial action and } \\
\text { mediate vasomotor tone. }\end{array}$ & -Migraine \\
\hline HTR1B $^{58,62,63}$ & rs6297 & $6 q 14.1$ & $\begin{array}{l}\text { Serotonin receptor 1B. } \\
\text { Serotonin is known to have } \\
\text { direct endothelial action and } \\
\text { mediate vasomotor tone. }\end{array}$ & -Migraine \\
\hline HTR2A $^{58,62,63}$ & $\begin{array}{l}\text { rs2070040 } \\
\text { rs6313 }\end{array}$ & $13 q 14.2$ & $\begin{array}{l}\text { Serotonin receptor } 2 \mathrm{~A} \text {. } \\
\text { Serotonin is known to have } \\
\text { direct endothelial action and } \\
\text { mediate vasomotor tone. }\end{array}$ & -Migraine \\
\hline $\mathrm{MAOA}^{14,58,77}$ & $\begin{array}{l}30 \text { bp VNTR } \\
\text { rs6323 }\end{array}$ & Xp11.3 & $\begin{array}{l}\text { Monoamine oxidase type A. } \\
\text { An enzyme involved in } \\
\text { metabolism of } \\
\text { catecholamine-based } \\
\text { neurotransmitter, with } \\
\text { some subtypes displaying } \\
\text { high affinity for serotonin. }\end{array}$ & $\begin{array}{l}\text {-Migraine } \\
\text {-Aggression in TBI } \\
\text { patients with PFC } \\
\text { lesions }\end{array}$ \\
\hline $\mathrm{MTDH}^{58}$ & rs1835740 & $8 q 22.1$ & $\begin{array}{l}\text { Metadherin. A cell surface } \\
\text { protein with a } \\
\text { transmembrane domain. } \\
\text { Involved in glutamate } \\
\text { homeostasis. }\end{array}$ & $\begin{array}{l}\text {-Migraine } \\
\text {-Potential } \\
\text { involvement in } \\
\text { glutamate } \\
\text { mediated } \\
\text { excitotoxicity } \\
\end{array}$ \\
\hline $\operatorname{SLC} 1 A 2^{58,82}$ & rs3794087 & $11 \mathrm{p} 13$ & $\begin{array}{l}\text { Excitatory amino acid } \\
\text { transporter } 2 \text {. A glutamate } \\
\text { transporter that regulates } \\
\text { CNS glutamate levels. } \\
\text { Mutations are linked to } \\
\text { impaired transport of }\end{array}$ & $\begin{array}{l}\text {-Glutamate- } \\
\text { mediated } \\
\text { excitotoxicity } \\
\text {-Migraine }\end{array}$ \\
\hline
\end{tabular}




\begin{tabular}{|c|c|c|c|c|}
\hline & & & $\begin{array}{l}\text { glutamate and increased } \\
\text { excitotoxicity. }\end{array}$ & \\
\hline SLC6A4 ${ }^{14,58,76}$ & $\begin{array}{l}\text { rs25531 } \\
\text { VNTR S Tin2 }\end{array}$ & $17 q 11.2$ & $\begin{array}{l}\text { Sodium-dependent } \\
\text { serotonin transporter }\end{array}$ & $\begin{array}{l}\text {-Post-TBI } \\
\text { depression } \\
\text {-Migraines }\end{array}$ \\
\hline SLC17A7 $7^{14,83}$ & rs74144284 & $19 q 13.33$ & $\begin{array}{l}\text { Vesicular glutamate } \\
\text { transporter } 1 . \text { Regulates } \\
\text { CNS levels of glutamate. } \\
\text { Mutations lead to increased } \\
\text { excitotoxicity. }\end{array}$ & $\begin{array}{l}\text {-Prolonged } \\
\text { recovery in TBI. }\end{array}$ \\
\hline
\end{tabular}

BDNF = brain derived neurotrophic factor, $\mathrm{CACN}$ = calcium channel, CALCA = calcitonin related polypeptide alpha, $\mathrm{COMT}=$ catechol-O-methyltransferase, $\mathrm{CNS}=$ central nervous system, $\mathrm{GRIN}=\mathrm{HTR}=$ serotonin receptor, $\mathrm{MAO}=$ monoamine oxidase, $\mathrm{MTDH}=$ metadherin, NMDA = n-methyl d-aspartate, $\mathrm{PFC}=$ pre-frontal cortex, $\mathrm{RCVS}=$ reversible cerebral vasoconstriction syndrome, $\mathrm{rs}$ = reference number for SNP, SCD = spreading cortical depression, SLC = solute carrier, SNP = single nucleotide polymorphism, $\mathrm{TBI}=$ traumatic brain injury, VNTR = variable number tandem repeat. *All SNP information was gained from the referenced literature in the manuscript, table and through both ClinVar and dbSNP online databases. 
Table 4 | Candidate single nucleotide polymorphisms linked to metabolic effects on cerebral autoregulation.

\begin{tabular}{|c|c|c|c|c|}
\hline Gene name & $\begin{array}{l}\frac{\text { Variant- }}{\text { associated }} \\
\text { Polymorphism: rs } \\
\begin{array}{l}\text { number or } \\
\text { mutation }\end{array}\end{array}$ & Chromosome & Protein and role & $\begin{array}{l}\text { Relevant } \\
\text { pathological } \\
\text { conditions } \\
\text { associated to date } \\
\text { with } \\
\text { Polymorphisms }\end{array}$ \\
\hline AQP4 $4^{14,93}$ & $\begin{array}{l}\text { rs3763043 } \\
\text { rs3875089 }\end{array}$ & $18 q 11.2$ & $\begin{array}{l}\text { Encodes for aquaporin-4 } \\
\text { channel, the main } \\
\text { astrocytic foot process } \\
\text { water channel involved in } \\
\text { water homeostasis across } \\
\text { the BBB. } \\
\text { Mutation leads to loss of } \\
\text { function. }\end{array}$ & $\begin{array}{l}\text {-Cerebral edema } \\
\text {-Global outcome in } \\
\text { TBI }\end{array}$ \\
\hline $\begin{array}{l}\text { ATPBC-B1 } \\
(\text { ABCB1 } 1)^{14,91,92}\end{array}$ & rs1045642 & $7 q 21.12$ & $\begin{array}{l}\text { Encodes for BBB } \\
\text { transporter, ATP-binding } \\
\text { cassette subtype B1. } \\
\text { Mutation leads to loss of } \\
\text { function. }\end{array}$ & $\begin{array}{l}\text {-Linked to global } \\
\text { outcome in TBI }\end{array}$ \\
\hline $\begin{array}{l}\text { ATPBC-C1 } \\
(A B C C 1)^{1491,92}\end{array}$ & rs4148382 & $16 p 13.11$ & $\begin{array}{l}\text { Encodes for BBB } \\
\text { transporter, ATP-binding } \\
\text { cassette subtype C1. } \\
\text { Mutation leads to loss of } \\
\text { function. }\end{array}$ & $\begin{array}{l}\text {-Linked to global } \\
\text { outcome in TBI }\end{array}$ \\
\hline $\begin{array}{l}\text { ATPBC-C8 } \\
(\text { ABCC } 8)^{14,91,92}\end{array}$ & $\begin{array}{l}\text { rs2283261 } \\
\text { rs3819521 } \\
\text { rs2283258 } \\
\text { rs1799857 }\end{array}$ & $11 p 15.1$ & $\begin{array}{l}\text { Encodes for BBB } \\
\text { transporter, ATP-binding } \\
\text { cassette subtype C8. } \\
\text { Mutation leads to loss of } \\
\text { function. }\end{array}$ & $\begin{array}{l}\text {-Linked to cerebral } \\
\text { edema in TBI }\end{array}$ \\
\hline $\begin{array}{l}\text { mtDNA } \\
\text { haplotypes }\end{array}$ & $\begin{array}{l}\text { Haplotypes - J, T, } \\
\text { U, K }\end{array}$ & mtDNA & $\begin{array}{l}\text { Mediates aerobic } \\
\text { metabolism, amongst } \\
\text { other functions. }\end{array}$ & $\begin{array}{l}\text {-Linked to global } \\
\text { outcome in TBI }\end{array}$ \\
\hline
\end{tabular}




\begin{tabular}{|c|c|c|c|c|}
\hline $\mathrm{mtDNA}^{90}$ & $\begin{array}{l}-10398 \mathrm{~A} \text { mutation } \\
-10398 \mathrm{G} \text { mutation }\end{array}$ & mtDNA & $\begin{array}{l}\text { Mediates aerobic } \\
\text { metabolism, amongst } \\
\text { other functions. }\end{array}$ & $\begin{array}{l}\text {-Linked to global } \\
\text { outcome in TBI }\end{array}$ \\
\hline$M M P 2^{58}$ & rs2285053 & $16 p 12.2$ & $\begin{array}{l}\text { Encodes for matrix } \\
\text { metalloproteinase-2, } \\
\text { involved in degrading } \\
\text { extracellular proteins. }\end{array}$ & -Migraine \\
\hline $\mathrm{MMP3}^{58}$ & rs35068180 & $11 q 22.2$ & $\begin{array}{l}\text { Encodes for matrix } \\
\text { metalloproteinase-3, } \\
\text { involved in degrading } \\
\text { extracellular proteins. }\end{array}$ & -Migraine \\
\hline $\mathrm{MMP9}^{58}$ & $\begin{array}{l}\text { rs3918242 } \\
\text { rs2234681 } \\
\text { rs17576 }\end{array}$ & $20 q 13.12$ & $\begin{array}{l}\text { Encodes for matrix } \\
\text { metalloproteinase-9, } \\
\text { involved in degrading } \\
\text { extracellular proteins. }\end{array}$ & -Migraine \\
\hline
\end{tabular}

$A B C C=A T P$ binding cassette,$A Q P=$ aquaporin,$A T P=$ adenosine triphosphate,$A T P B C=$ adenosine triphosphate binding cassette, $\mathrm{BBB}=$ blood brain barrier, $\mathrm{MMP}=$ matrix metalloproteinase, $\mathrm{mtDNA}$ $=$ mitochondrial SNA, $\mathrm{rS}=$ reference number for SNP, SNP = single nucleotide polymorphism, TBI = traumatic brain injury. *All SNP information was gained from the referenced literature in the manuscript, table and through both ClinVar and dbSNP online databases. 